\title{
Genetic Diversity as Revealed by Intersimple Sequence Repeat Polymorphism in Narcissus Accessions to Identify the Tolerant Genotypes for Deficit Irrigation
}

\author{
Mozhgan Zangeneh and Hassan Salehi ${ }^{1}$ \\ Department of Horticultural Science, School of Agriculture, Shiraz University, Shiraz, Iran
}

\begin{abstract}
AdDitional INDEX words. catalase, ISSR markers, Narcissus tazetta, peroxidase, proline, superoxide dismutase
Aвstract. There are many species of Narcissus in diverse areas of the world in natural or cultured form and there is no complete information about their genetic status, especially the relatedness within a species. Thus, the current study applied intersimple sequence repeat (ISSR) markers to estimate the genetic diversity of $\mathbf{3 1}$ accessions, including 30 accessions of Narcissus tazetta, collected from 16 regions of Iran and one known exotic narcissus species that is being cultivated in Iran, and identification of tolerant genotypes for deficit irrigation by evaluation of their morphophysiological characteristics. Seventeen anchored ISSR primers from a total of 19 tested ISSR primer pairs were used and produced 206 bands of different sizes. The average percentage of polymorphic bands was $96.02 \%$. The maximum resolving power (8.32), polymorphic information content average $(0.44)$, and marker index values (5.61) were observed for the primers of 811,828 , and 811, respectively. The unweighted pair group method with arithmetic mean based on Jaccard's coefficients was used to assign the genotypes to one of two major clusters. Both clusters were divided into two subclusters, with single and double flowers separating into subgroups. The results showed that ISSR markers can be used as a diagnostic tool to evaluate genetic variation in Narcissus genotypes and reveal their relationships. The results of screening study identified drought-tolerant accessions. They were clustered into two major groups: drought-tolerant accessions with single flowers and drought-sensitive accessions having double and semidouble flowers. The findings presented can be used in breeding programs for different Narcissus genotypes.
\end{abstract}

Flowering bulbs, or ornamental geophytes (Alam et al., 2013; De Hertogh and Le Nard, 1993), show variation in morphological, developmental, biological, and physiological reactions to environmental elements. They are significant contributors to the universal ornamental trade and profitably used for bulb and flower production of outdoor and potted plants and fresh-cut flowers, as well for landscaping in private gardens. Although ornamental geophytes constitute more than 800 genera, the industry is controlled by only seven: Tulipa, Lilium, Narcissus, Gladiolus, Hyacinthus, Crocus, and Iris (Kamenetsky and Okubo, 2013).

Narcissus is a member of the Amaryllidaceae family, which comprises 65 genera and more than 860 species. These species are broadly dispersed in tropical, subtropical, and temperate areas of the northern and southern hemispheres (Hanks, 2003). They possess highly decorative characteristics and have been used in floriculture and medicine since ancient times (Artyushenko, 1970; Khamidkhodzhaev, 1984). Amaryllids are important decorative ornamentals and are popular for indoor and outdoor use as both winter and spring coloring (Hanks, 2003). In addition, plants belonging to the Amaryllidaceae have been identified as possessing alkaloids that encompass a range of biological activity (Pigni et al., 2010).

Researchers have been able to isolate more than 200 alkaloids from the plants of this family (Hanks, 2003). Within this group, the genus Narcissus is used in traditional medicine to treat a variety of health problems. A range of pharmacological effects has been attributed to these alkaloids, and include antiviral, antifungal, and antitumor activity (Pigni et al.,

Received for publication 29 Oct. 2018. Accepted for publication 28 Jan. 2019. ${ }^{1}$ Corresponding author. E-mail: hsalehi@shirazu.ac.ir.
2010). Due to their delicate odor, the fragrance of narcissus flowers is popular for use in luxury perfumes. Among these species, Narcissus poeticus, $N$. tazetta, and Narcissus jonquilla are notable (Ruiz-Ramon et al., 2014). The complexity of Narcissus relates to the ease in which hybridization occurs naturally as well as by cultivation, breeding, selection, escape, and naturalization (Hanks, 2003).

Based on chromosomal studies of the genus, Fernandes (1968) separated Narcissus into two subgenera [Hermione $(x=5)$ and Narcissus $(x=7)]$ and 10 sections. Principally, Narcissus has a Mediterranean distribution with a center of diversity on the Iberian Peninsula. The genus also can occur in southwestern France, northern Africa, and eastward to Greece. $N$. tazetta is primarily found in Spain and northern Africa, as well as in a narrow band within China and Japan.

The development of effective conservation and management strategies requires a thorough understanding of the genetic diversity and relationships between the plant varieties to identify gaps in the germplasm collection (Nayanakantha et al., 2010). Identification of plant genotypes can be conducted through morphological, enzymatic, and genetic quantification strategies (Pivoriene and Pasakinskiene, 2008; Qian et al., 2001). Morpho-chemical characteristics are dependent on age and environment (Deore and Samantaray, 2015; Nayanakantha et al., 2010). Because they are largely free from environmental influence, DNA-based molecular markers have been applied extensively to measure genetic diversity (Deore and Samantaray, 2015).

Randomly amplified polymorphic DNA (RAPD) technology was used by Chehrazi et al. (2008) to discover the genetic relationship between the endemic and exotic narcissus. Nine main groups were identified. Using microsatellite 
Table 1. The accessions of Narcissus tazetta collected from different regions of Iran.

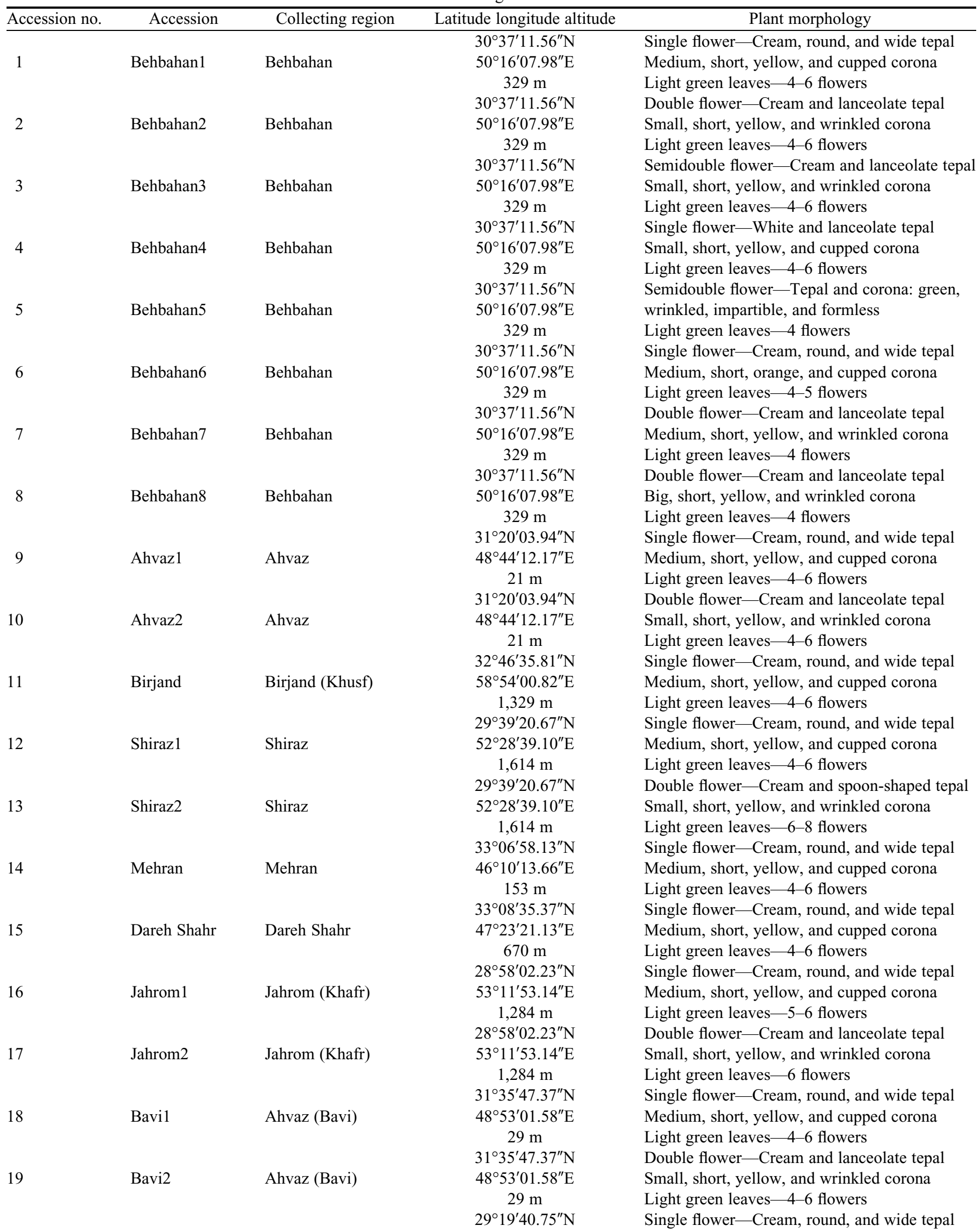


Table 1. Continued.

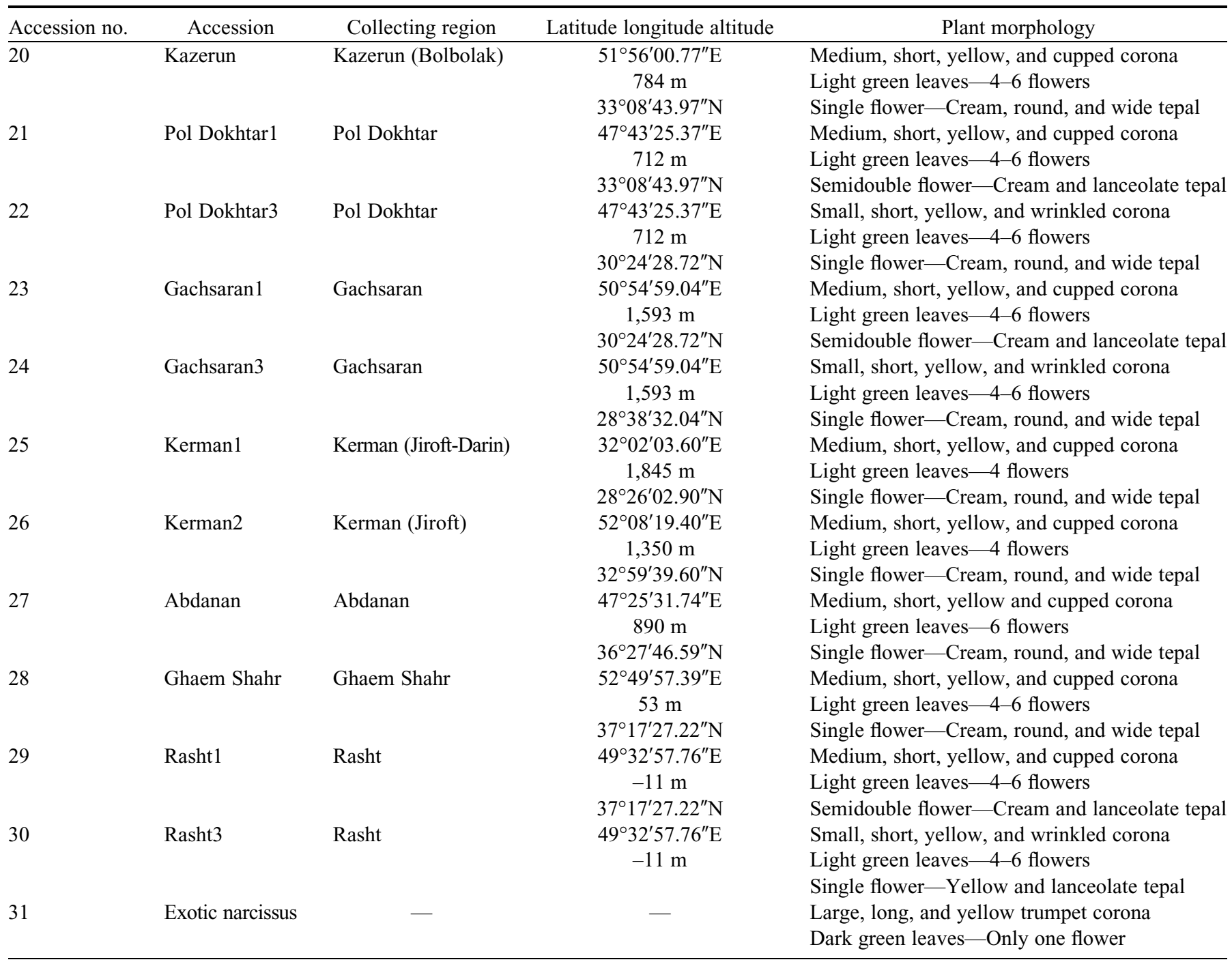

and chloroplast DNA, Hodgins and Barrett (2007) studied the population structure and genetic diversity of Narcissus triandrus. Lu et al. (2007) applied amplified fragment length polymorphism (AFLP) and RAPD markers to investigate the influence of irradiation on Chinese Narcissus for the purpose of analyzing its genetic variation.

Tucci et al. (2004) studied two species, namely $N$. poeticus and Narcissus radiiflorus populations originating from two geographically different locations. Each species was examined using AFLP markers. Interestingly, the results from cluster analysis and principal coordinate analysis ( $\mathrm{PCoA})$ of the computed similarity matrix showed that the genetic distance between individuals belonging to different populations of the same species was somewhat more than those between species.

Medrano et al. (2014) used AFLP markers for the purpose of studying genetic lines in an endemic population of daffodil (Narcissus pseudonarcissus) for which the taxonomic distinctions were problematic. The results identified well-defined ancestries of daffodil, which exist all over the southern highlands of the Iberian Peninsula. These findings strongly support the taxonomical definition of this lineage and its qualifying as a distinct part of conservation.
One method for the genetic mapping and genetic estimation of germplasm resources is using SSR markers (Estoup and Angers, 1998; McCough et al., 1997). A major limitation of this method is its requirement of distinguishing the flanking sequences to design species-specific primers for SSR polymorphism. Us of inter-SSR (ISSR) markers is an alternative method that overcomes most weaknesses of other markers (Gupta et al., 1994; Meyer et al., 1993; Pradeep Reddy et al., 2002; Wu et al., 1994; Zietkiewicz et al., 1994). This technique requires only a small amount of template DNA and does not need genome sequence information for the purpose of primer construction. ISSR markers also offer a random distribution all over the genome, resulting in the production of several fragments per reaction (Shi et al., 2010).

In ISSR, SSR motifs are primarily applied to amplify the ISSR regions (Tautz and Renz, 1984). The technique uses single primers of 16 to 25 nucleotides that are generally anchored at the $3^{\prime}$ or $5^{\prime}$ ends with one to four degenerate bases extended into the flanking sequences (Godwin et al., 1997; Zietkiewicz et al., 1994). ISSR-polymerase chain reaction (PCR) is commonly used in eras of genetic diversity, gene tagging, phylogenetic studies, genome mapping, 
and evolutionary biology for a series of plant species (Pradeep Reddy et al., 2002). ISSRs have been effectively used to evaluate the degree of genetic diversity at the inter- and intraspecies levels for plant species such as aloe [Aloe barbadensis (Deore and Samantaray, 2015)]; onion, garlic, and leek [Allium cepa, Allium sativum, and Allium porrum, respectively (Mukherjee et al., 2013)]; an uncommon endemic orchid in China [Calanthe tsoongiana (Qian et al., 2013)], jasmine [Jasminum sp. (Ghasemi Ghehsareh et al., 2014)], three genera from the Iridaceae family (Raycheva et al., 2011), tall fescue [Festuca arundinacea (Salehi et al., 2014)], melon [Cucumis melo (Monforte et al., 2003)], tulip [Tulipa sp. (Kiani et al., 2012)], trifoliate orange [Poncirus trifoliata (Fang et al., 1997)], and several other species of wild and cultivated plants. The objective of this investigation was to apply ISSR-PCR to determine the genetic diversity of available accessions of Narcissus species in Iran, and identification of tolerant genotypes for deficit irrigation by evaluation of their morpho-physiological characteristics.

Drought is a major abiotic stress that affects the growth of plants and is caused by low water availability in arid and semiarid regions or due to changes in precipitation (Toker et al., 2007). During environmental stresses such as drought, reactive oxygen species (ROS) are increasingly produced. ROS negatively affect the growth and development of plants (Rahimizadeh et al., 2007) and is thought to be a contributing factor to stress damage and for quick cellular injury that occurs when plants are exposed to stress (Yong et al., 2006). ROS damages proteins, membrane lipids, and nucleic acids (Foyer et al., 1994). Activated oxygen also causes protein denaturation, lipid peroxidation, and DNA mutation at higher oxidative stress levels
(Baby and Jini, 2011). When plants are exposed to drought stress, antioxidants function as a protective mechanism against free radicals and increase the activity and amount of antioxidant enzymes, such as superoxide dismutase (SOD), catalase (CAT), peroxidase (POX), and an amino acid (proline) in plant cells (Rahimizadeh et al., 2007). Information about the significant morpho-physiological characteristics of Narcissus accessions can be applied to breeding programs to detect accessions resistant to drought stress; thus, we investigated the physiological and morphological traits of some Narcissus accessions under water-sufficient and water-deficient conditions.

\section{Materials and Methods}

EXPerimental SITE AND Plant material. The assay was performed in the Central Laboratory and Biotechnology Laboratory of the College of Agriculture at Ramin University, Ahvaz, Iran. Thirty accessions of $N$. tazetta from 16 regions of Iran and one commercial exotic species of Narcissus (N. pseudonarcissus) were used in this research (Table 1).

Extraction OF GENOMic DNA. Genomic DNA was extracted from young leaves using the standard CTAB method proposed by Doyle and Doyle (1990) with minor alterations. Leaf samples $(0.1 \mathrm{~g})$ were ground in liquid $\mathrm{N}_{2}$ and the leaf powder was immediately transferred to two centrifuge tubes with $800 \mu$ Lof extraction buffer [2\% (w/v) CTAB, $1.4 \mathrm{M} \mathrm{NaCl}$, $20 \mathrm{~mm} \mathrm{Na}_{2}$ EDTA (pH 8), $100 \mathrm{~mm}$ Tris- $\mathrm{HCl}(\mathrm{pH} 8), 0.5 \%$ (w/v) polyvinylpyrrolidone, $1 \%(\mathrm{v} / \mathrm{v}) 2$-mercaptoethanol] that had been prewarmed to $65^{\circ} \mathrm{C}$. The sample was kept at $65^{\circ} \mathrm{C}$ for 30 $\mathrm{min}$ and the centrifuge tubes were inverted for $10 \mathrm{~min}$. It then was mixed with $500 \mu \mathrm{L}$ of chloroform-isoamyl alcohol (24:1)

Table 2. List of intersimple sequence repeat (ISSR) primers and results of experiments performed among 31 Narcissus accessions using ISSR markers.

\begin{tabular}{|c|c|c|c|c|c|c|c|c|c|c|}
\hline Primer no. & $\begin{array}{l}\text { Sequence } \\
\left(5^{\prime}-3^{\prime}\right)^{z}\end{array}$ & $\begin{array}{l}\text { Annealing } \\
\text { temp }\left({ }^{\circ} \mathrm{C}\right)\end{array}$ & $\begin{array}{l}\text { Fragment size } \\
\text { range (bp) }\end{array}$ & Loci (no./primer) & $\begin{array}{l}\text { Polymorphic } \\
\text { loci (no.) }\end{array}$ & $\operatorname{Pp}(\%)^{\mathrm{y}}$ & $\mathrm{EMR}^{\mathrm{y}}$ & $\mathrm{PIC}^{\mathrm{y}}$ & $\mathrm{MI}^{\mathrm{y}}$ & $\mathrm{Rp}^{\mathrm{y}}$ \\
\hline 807 & $(\mathrm{AG}) 8 \mathrm{~T}$ & 32.6 & $400-1,700$ & 9 & 9 & 100 & 9 & 0.26 & 2.34 & 3.35 \\
\hline 808 & $(\mathrm{AG}) 8 \mathrm{C}$ & 36 & $390-1,000$ & 6 & 6 & 100 & 6 & 0.32 & 1.92 & 3.09 \\
\hline 810 & (GA)8T & 34.3 & $290-1,100$ & 15 & 14 & 93.33 & 13.06 & 0.21 & 2.74 & 4.19 \\
\hline 811 & $(\mathrm{GA}) 8 \mathrm{C}$ & 34.3 & $280-1,150$ & 17 & 17 & 100 & 17 & 0.33 & 5.61 & 8.32 \\
\hline 816 & $(\mathrm{CA}) 8 \mathrm{~T}$ & - & - & - & - & - & - & - & - & - \\
\hline 827 & (AC) $8 \mathrm{G}$ & 42.7 & $320-1,400$ & 10 & 7 & 70 & 4.9 & 0.15 & 0.73 & 2 \\
\hline 828 & (TG) $8 \mathrm{~A}$ & 37 & $520-920$ & 7 & 7 & 100 & 7 & 0.44 & 3.08 & 4.9 \\
\hline 829 & (TG)8C & 43.4 & $570-1,400$ & 6 & 6 & 100 & 6 & 0.31 & 1.86 & 2.77 \\
\hline 830 & (TG)8G & 42.3 & $470-1,300$ & 10 & 10 & 100 & 10 & 0.28 & 2.8 & 4.19 \\
\hline 835 & (AG)8YC & 35 & $280-1,250$ & 15 & 14 & 93.33 & 13.06 & 0.29 & 3.78 & 6.97 \\
\hline 840 & (GA)8YT & 35 & $270-1,200$ & 11 & 11 & 100 & 11 & 0.29 & 3.19 & 4.77 \\
\hline 861 & $(\mathrm{ACC}) 6$ & - & - & - & - & - & - & - & - & - \\
\hline \multirow[t]{3}{*}{ ALO } & (GTG)3GC & 38.5 & $400-1,500$ & 14 & 14 & 100 & 14 & 0.17 & 2.38 & 3.35 \\
\hline & & & Total & 206 & 198 & - & - & - & - & - \\
\hline & & & Mean & 12.11 & 11.65 & 96.02 & - & - & - & - \\
\hline
\end{tabular}

${ }^{\mathrm{z}} \mathrm{Y}=$ cytosine $(\mathrm{C})$ or thymine $(\mathrm{T})$.

${ }^{\mathrm{y}} \mathrm{Pp}=$ polymorphic percentage; $\mathrm{EMR}=$ effective multiple ratio; $\mathrm{EMR}=\mathrm{np}(\mathrm{np} / \mathrm{n})$, where $\mathrm{np}=$ number of polymorphic loci and $\mathrm{n}=$ total number of loci; PIC $=$ polymorphic information content $\left[=1-\mathrm{pi}^{2}-\mathrm{qi}^{2}\right.$ (Powell et al., 1996)], where $\mathrm{p}$ is frequency of visual alleles and $\mathrm{q}$ is the frequency of null alleles; MI $=$ marker index $\left[=\mathrm{PIC} \times \mathrm{EMR}\left(\right.\right.$ Powell et al., 1996)]; Rp $=$ resolving power $\left[=\sum \mathrm{Ib}, \mathrm{Ib}=1-(2 \times|0.5-\mathrm{p}|)\right]$. 
and slowly shaken for $30 \mathrm{~min}$, then centrifuged at $13,000 \mathrm{~g}_{\mathrm{n}}$ for $10 \mathrm{~min}$ at $4{ }^{\circ} \mathrm{C}$. The supernatant was collected and the same amount of cold isopropanol was added. After incubation for 20 min at $-20{ }^{\circ} \mathrm{C}$, the mixture was centrifuged at $13,000 g_{\mathrm{n}}$ for 10 $\min$ at $4{ }^{\circ} \mathrm{C}$.

The aqueous phase was discarded and the pelleted DNA was washed twice with $500 \mu$ Lof $70 \%$ ethanol and again centrifuged
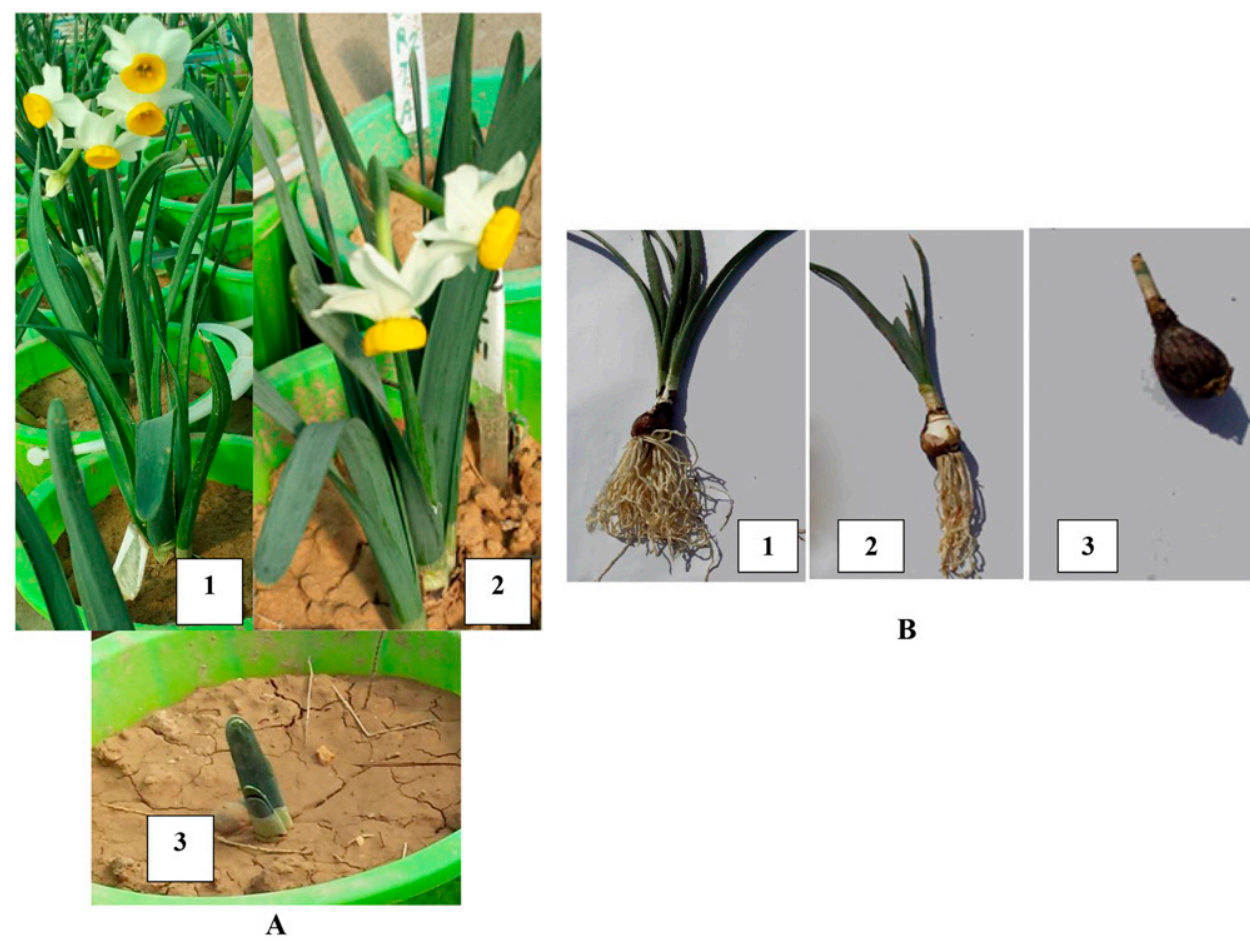

B

Fig. 1. Narcissus tazetta at (A) Flowering stage; $1=$ water-sufficient condition $[100 \%$ field capacity $(\mathrm{FC})], 2=$ drought-tolerant accession in water-stress condition ( $25 \% \mathrm{FC})$, and $3=$ drought-sensitive accession in water-stress condition $(25 \%$ FC). (B) Vegetative stage; 1 = water-sufficient condition ( $100 \%$ FC), 2 = drought-tolerant accession in water-stress condition ( $25 \% \mathrm{FC})$, and $3=$ drought-sensitive accession in water-stress condition (25\% FC). at $4{ }^{\circ} \mathrm{C}$ for $10 \mathrm{~min}$ at $13,000 \mathrm{~g}_{\mathrm{n}}$ and then dried. Extracted DNA samples were resuspended with $50 \mu \mathrm{L}$ double-distilled water $\left(\mathrm{ddH}_{2} \mathrm{O}\right)$ and were kept at $-20{ }^{\circ} \mathrm{C}$ until used. The quantity and quality of DNA were determined using spectrophotometer (NanoDrop 2000; Thermo Fisher Scientific, Waltham, MA) and $1 \%$ agarose gel electrophoresis. The concentrations of the extracted DNA samples were measured by absorption at 260 $\mathrm{nm}$, and the ratios $\mathrm{A} 260 / 280$ and A260/230 were used to estimate the amount of contamination, such as proteins, polyphenolic compounds, sugars, and lipids (Raycheva et al., 2011). Finally, the DNA samples were diluted to $\approx 50 \mathrm{ng} \cdot \mu \mathrm{L}^{-1}$ for use in the ISSR assay.

PRIMERS AND ISSR AMPLIFICATION. In this study, 19 ISSR primers (Takapouzist, Tehran, Iran) were selected that amplified $A$. серa, $A$. sativum, and $A$. porrum accessions (Mukherjee et al., 2013); Tulipa accessions (Kiani et al., 2012); and $A$. barbadensis accessions (Deore and Samantaray, 2015). These di- and trinucleotide repeat primers were used to generate band profiles. The 19 anchored primers were screened for polymorphisms on DNA samples from 31 Narcissus accessions. The primers were selected based on the number of polymorphic fragments produced, band size, amplification intensity, and reproducibility. Two primers were excluded because their banding patterns were difficult to score accurately on $2 \%$ agarose

Table 3. Sample size (N), number of alleles $(\mathrm{Na})$, number of effective alleles $(\mathrm{Ne})$, Nei's genetic diversity (I), Shannon's information index (He), and percentage of polymorphic loci $(\mathrm{Pp})$, of Narcissus populations collected from different regions of Iran.

\begin{tabular}{|c|c|c|c|c|c|c|c|}
\hline \multirow[b]{2}{*}{ Population } & \multirow[b]{2}{*}{$\mathrm{N}$} & $\mathrm{Na}$ & $\mathrm{Ne}$ & I & $\mathrm{He}$ & \multirow[b]{2}{*}{$\mathrm{Pp}$} & \multirow{2}{*}{$\begin{array}{c}\text { Bands } \\
\text { (no.) } \\
\end{array}$} \\
\hline & & \multicolumn{4}{|c|}{$(\mathrm{SE})$} & & \\
\hline Behbahan & 8 & $1.218(0.061)$ & $1.325(0.027)$ & $0.275(0.020)$ & $0.185(0.014)$ & 51.94 & 144 \\
\hline Ahvaz & 2 & $0.733(0.054)$ & $1.144(0.020)$ & $0.123(0.017)$ & $0.084(0.012)$ & 20.39 & 109 \\
\hline Birjand (Khusf) & 1 & $0.466(0.035)$ & $1.000(0.000)$ & $0.000(0.000)$ & $0.000(0.000)$ & 0.00 & 96 \\
\hline Kerman (Giroft) & 2 & $0.718(0.055)$ & $1.144(0.020)$ & $0.123(0.017)$ & $0.084(0.012)$ & 20.39 & 106 \\
\hline Mehran & 1 & $0.374(0.034)$ & $1.000(0.000)$ & $0.000(0.000)$ & $0.000(0.000)$ & 0.00 & 77 \\
\hline Abdanan & 1 & $0.461(0.035)$ & $1.000(0.000)$ & $0.000(0.000)$ & $0.000(0.000)$ & 0.00 & 95 \\
\hline Ghachsaran & 2 & $0.937(0.055)$ & $1.199(0.022)$ & $0.170(0.019)$ & $0.117(0.013)$ & 28.16 & 135 \\
\hline Pol Dokhtar & 2 & $0.650(0.049)$ & $1.096(0.017)$ & $0.082(0.014)$ & $0.056(0.010)$ & 13.59 & 106 \\
\hline Ghaem Shahr & 1 & $0.485(0.035)$ & $1.000(0.000)$ & $0.000(0.000)$ & $0.000(0.000)$ & 0.00 & 100 \\
\hline Rasht & 2 & $0.845(0.056)$ & $1.182(0.022)$ & $0.156(0.018)$ & $0.107(0.013)$ & 25.73 & 121 \\
\hline Bavi & 2 & $0.733(0.050)$ & $1.110(0.018)$ & $0.094(0.015)$ & $0.064(0.010)$ & 15.53 & 119 \\
\hline
\end{tabular}


gels; thus, 17 primers were selected for further study (Table 2).

The primers were applied to amplify the interrepeat motifs in the genomic DNA of the Narcissus accessions using a standard PCR protocol with some alterations. PCR was performed with $25-\mu \mathrm{L}$ reactions, including $17.05 \mu \mathrm{L}$ sterile $\mathrm{ddH}_{2} \mathrm{O}, 2.5 \mu \mathrm{L}$ of $10 \mathrm{X}$ assay buffer, $0.75 \mu \mathrm{L} \mathrm{MgCl}_{2}, 0.5 \mu \mathrm{L}$ dNTP $(10 \mathrm{~mm}$ total, $2.5 \mathrm{~mm}$ each), $2 \mu \mathrm{L}$ primer, $0.2 \mu \mathrm{L}\left(5 \mathrm{U} \cdot \mu \mathrm{L}^{-1}\right)$ Taq-DNA polymerase (Sinnagen, Tehran, Iran), and $2 \mu \mathrm{L}$ genomic DNA $\left(50 \mathrm{ng} \cdot \mu \mathrm{L}^{-1}\right)$. A sample without genomic DNA was used as the negative control in each assay. The amplification reactions were carried out in a thermal cycler (iCycler; Bio-Rad Laboratories, San Diego, CA) under the following conditions: initial denaturation at $94{ }^{\circ} \mathrm{C}$ for 4 min followed by 40 amplification cycles of denaturation at $94{ }^{\circ} \mathrm{C}$ for $45 \mathrm{~s}$; primer annealing for $45 \mathrm{~s}$ at optimized temperature $\left(26.4\right.$ to $44.7^{\circ} \mathrm{C}$ depending on the kind of primer), and elongation at $72{ }^{\circ} \mathrm{C}$ for 1 min with a final extension at $72{ }^{\circ} \mathrm{C}$ for $4 \mathrm{~min}$.

The PCR products were electrophoresed on $2 \%$ agarose gels in $0.5 \mathrm{x}$ tris borate EDTA buffer stained with DNA safe stain dye $\left(0.025 \mu \mathrm{L} \cdot \mathrm{mL}^{-1}\right)$ by horizontal gel electrophoresis $(22 \times 18 \mathrm{~cm}$ with 25 wells) at $100 \mathrm{~V}$ for $4 \mathrm{~h}$, then the band profiles were visualized under ultraviolet light and photographed with a gel documentation and analysis system (JS-6800; UVITEC, Shanghai, China). The size of the amplified products was evaluated by comparing them with a 100-base pair (bp) ladder as the molecular size standard (Fermentas, St. Leon-Rot, Germany).

Data ANalysis. For genetic diversity analysis, each ISSR band was treated as a dominant allele for a particular fragment. Amplified bands of each fragment were scored based on the presence (1) and absence (0) of the bands. Only clear and reproducible fragments were scored and the data matrices of the ISSR fragments were accumulated for further investigation. These data were applied to generate a similarity matrix based on Jaccard's coefficients by using the SIMQUAL program in the NTSYS-PC software package version $2.02 \mathrm{e}$ (Rohlf, 1998). To construct the dendrogram, clustering was performed using the unweighted pair group method with arithmetic mean (UPGMA) based on Jaccard's coefficients. A Mantel test was used to calculate the coefficient of cophenetic correlation, which is a measure of the congruence of the similarity matrix and the dendrogram (Mantel, 1967).

The ability of each primer to differentiate between accessions was assessed by calculating their resolving power [Rp (Deore and Samantaray, 2015; Gilbert et al., 1999)], marker index [MI (Ghasemi Ghehsareh et al., 2014; Powell et al., 1996)], and polymorphic information content [PIC (Deore and Samantaray, 2015; Ghasemi Ghehsareh et al., 2014; Weising et al., 2005)]. PIC was calculated as PIC $=1-\mathrm{pi}^{2}-\mathrm{qi}^{2}$, where $\mathrm{p}$ is the band rate and $\mathrm{q}$ is no band rate (Chadha and Gopalakaishna, 2007; Deore and Samantaray, 2015). MI was calculated as $\mathrm{MI}=\mathrm{PIC} \times$ effective multiplex ratio $(\mathrm{EMR})$ and $\mathrm{Rp}=\sum \mathrm{Ib}$, $\mathrm{Ib}$ (band in formativeness $)=1-(2 \times[0.5-\mathrm{p}])$, where $\mathrm{p}$ is the proportion of each accession comprising the band (Ghasemi Ghehsareh et al., 2014). GenAlEx 6.4 (Peakall and Smouse, 2006) was used to calculate the percentage of polymorphic fragments, and the parameters of PIC, EMR, MI, and Rp were calculated by Excel (2010 for Windows; Microsoft Corp., Redmond, WA).

The diversity measures were calculated with Nei's (1978) genetic diversity index $(\mathrm{He})$ and Shannon information index

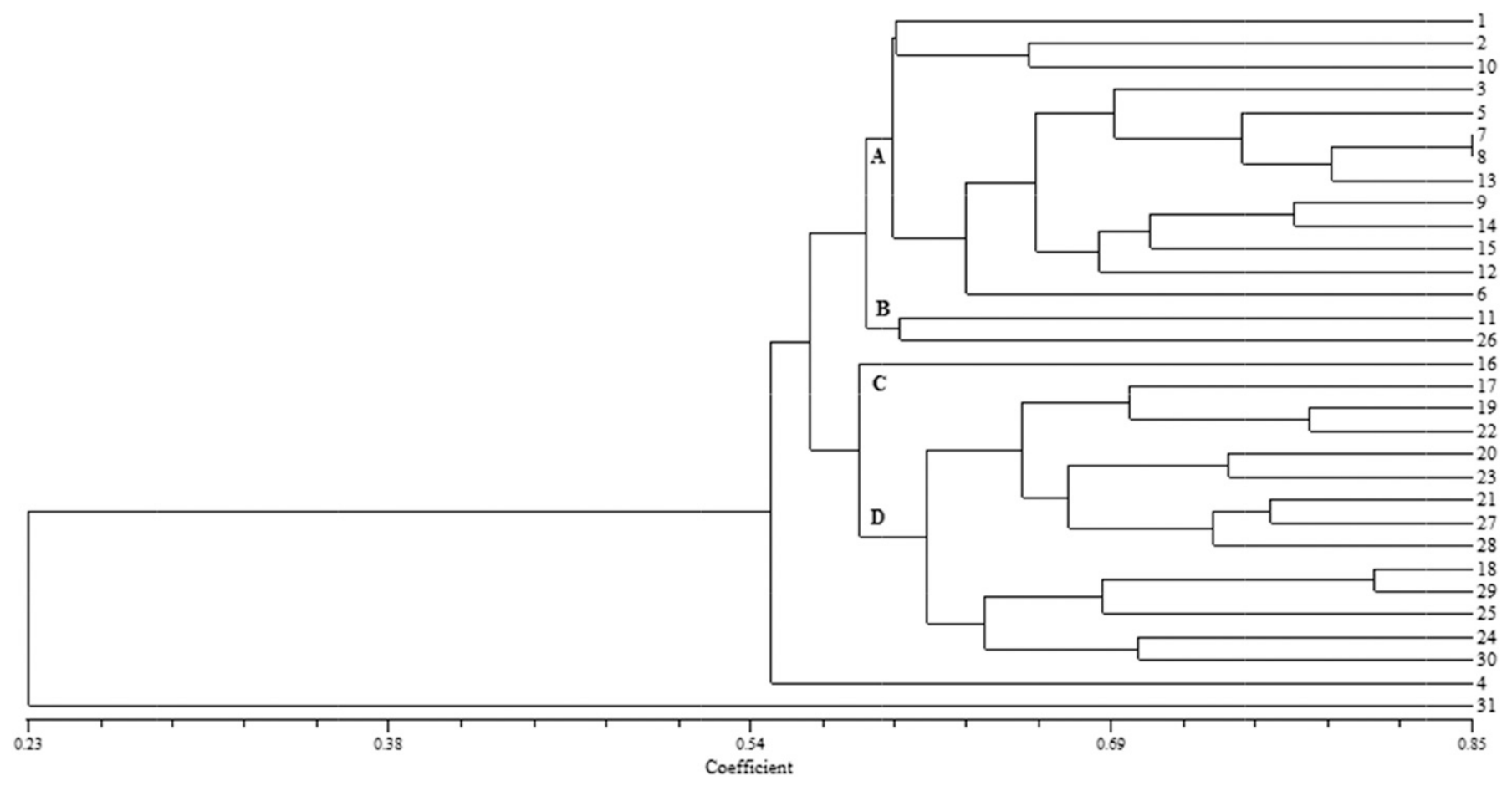

Fig. 2. Dendrogram based on unweighted pair group method with arithmetic mean of Jaccard's similarity matrix represents the genetic relatedness among 31 Narcissus accessions from different regions of Iran based on intersimple sequence repeat data. Regions of Iran: $1=$ Behbehan1, $2=$ Behbehan2, $3=$ Behbehan3, $4=$ Behbehan4, $5=$ Behbehan5, $6=$ Behbehan6, $7=$ Behbehan7, $8=$ Behbehan8, $9=$ Ahvaz1, $10=$ Ahvaz2, $11=$ Birjand, $12=$ Shiraz1, $13=$ Shiraz2, $14=$ Mehran, $15=$ Dareh Shahr, 16 = Jahrom1, $17=$ Jahrom2, $18=$ Bavi1, $19=$ Bavi2, 20 = Kazerun, $21=$ Pol Dokhtar1, 22 = Pol Dokhtar3, 23 = Gachsaran1, $24=$ Gachsaran3, $25=$ Kerman1, $26=$ Kerman2, $27=$ Abdanan, $28=$ Ghaem Shahr, $29=$ Rasht1, $30=$ Rasht3, $31=$ exotic narcissus. 
(I). GenAlEx 6.4 software was used to calculate the following genetic diversity parameters: pairwise genetic distance using Nei's genetic identity between populations,

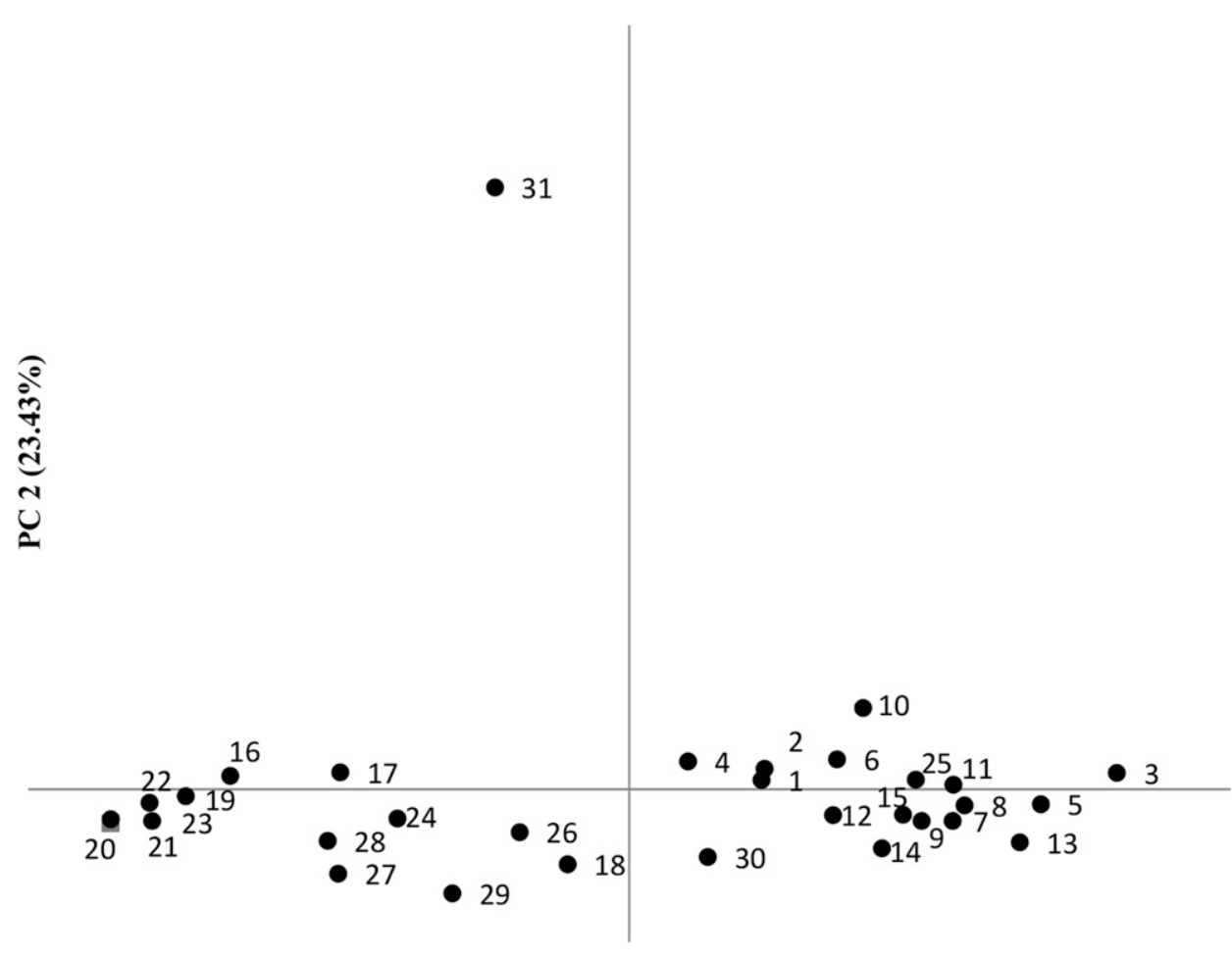

PC $1(25.23 \%)$

Fig. 3. Biplot derived from principal coordinate analysis $(\mathrm{PCoA})$ of genetic distance matrix based on intersimple sequence repeat data in 31 Narcissus accessions (PC 1 vs. 2) from different regions of Iran: $1=$ Behbehan1, $2=$ Behbehan2, $3=$ Behbehan3, $4=$ Behbehan4, $5=$ Behbehan5, $6=$ Behbehan6, $7=$ Behbehan7, $8=$ Behbehan8, $9=$ Ahvaz1, $10=$ Ahvaz2, $11=$ Birjand, $12=$ Shiraz1, $13=$ Shiraz2, $14=$ Mehran, $15=$ Dareh Shahr, $16=$ Jahrom1, $17=$ Jahrom2, $18=$ Bavi1, $19=$ Bavi2, $20=$ Kazerun, $21=$ Pol Dokhtar1, $22=$ Pol Dokhtar3, $23=$ Gachsaran1, $24=$ Gachsaran3, 25 = Kerman1, 26 = Kerman2, $27=$ Abdanan, $28=$ Ghaem Shahr, 29 = Rasht1, 30 = Rasht3, $31=$ exotic narcissus.
$\mathrm{He}$, I, effective number of alleles ( $\mathrm{Ne}$ ), and the percentage of polymorphic fragments. NTSYS-pc software (version 2.02e) was also used for PCoA to show the genetic relationships between accessions.

EXPERIMENTAL DESIGN TO DETERMINE DROUGHT STRESS RESPONSES. Endemic N. tazetta bulbs were harvested in July. Uniform-sized bulbs, after treatment with benomyl fungicide $(0.2 \%)$, were planted in the plastic containers (filled with clay loam soil) in last week of August and moved to a greenhouse under $25 \pm 5^{\circ} \mathrm{C}$ at planting time and gradually reached to $10 \pm 5^{\circ} \mathrm{C}$ at flowering time under $3000 \mathrm{~lx}, 12 \mathrm{~h}$ per day and $70 \%$ to $80 \%$ relative humidity. The assay was organized as a completely randomized design with three replications of two samples each. The plants were exposed to one of the following regimens: water-sufficient condition $[100 \%$ field capacity $(\mathrm{FC})]$ and water stress (25\% FC) (Fig. 1). At the end of the vegetative stage, fresh leaves were excised to calculate their physiological traits of CAT (Dhindsa et al., 1981), SOD (Beauchamp and Fridovich, 1971), and POX (Chance and Maehly, 1955) activity, proline and total protein contents, and relative water content (RWC). Morphological characteristics including fresh and dry weight ratio, number of bulblets, and dry weight of bulb were assessed as

Table 4. Nei's genetic identity between Narcissus populations collected from different regions of Iran by intersimple sequence repeat markers.

\begin{tabular}{|c|c|c|c|c|c|c|c|c|c|c|c|c|c|c|c|c|}
\hline Population no. ${ }^{\mathrm{z}}$ & 1 & 2 & 3 & 4 & 5 & 6 & 7 & 8 & 9 & 10 & 11 & 12 & 13 & 14 & 15 & 16 \\
\hline 1 & 1.000 & & & & & & & & & & & & & & & \\
\hline 2 & 0.903 & 1.000 & & & & & & & & & & & & & & \\
\hline 3 & 0.885 & 0.833 & 1.000 & & & & & & & & & & & & & \\
\hline 5 & 0.914 & 0.878 & 0.892 & 0.862 & 1.000 & & & & & & & & & & & \\
\hline 6 & 0.891 & 0.810 & 0.874 & 0.830 & 0.882 & 1.000 & & & & & & & & & & \\
\hline 7 & 0.742 & 0.733 & 0.726 & 0.680 & 0.735 & 0.723 & 1.000 & & & & & & & & & \\
\hline 9 & 0.873 & 0.816 & 0.822 & 0.833 & 0.859 & 0.847 & 0.784 & 0.850 & 1.000 & & & & & & & \\
\hline 10 & 0.831 & 0.770 & 0.816 & 0.774 & 0.809 & 0.797 & 0.788 & 0.806 & 0.900 & 1.000 & & & & & & \\
\hline 11 & 0.791 & 0.770 & 0.735 & 0.748 & 0.768 & 0.743 & 0.757 & 0.820 & 0.836 & 0.852 & 1.000 & & & & & \\
\hline 12 & 0.853 & 0.790 & 0.816 & 0.781 & 0.816 & 0.809 & 0.776 & 0.817 & 0.903 & 0.930 & 0.835 & 1.000 & & & & \\
\hline 13 & 0.845 & 0.828 & 0.833 & 0.812 & 0.842 & 0.808 & 0.794 & 0.823 & 0.911 & 0.877 & 0.810 & 0.853 & 1.000 & & & \\
\hline 14 & 0.842 & 0.793 & 0.816 & 0.803 & 0.849 & 0.816 & 0.767 & 0.769 & 0.879 & 0.869 & 0.796 & 0.863 & 0.860 & 1.000 & & \\
\hline
\end{tabular}

${ }^{\mathrm{z}} 1$ = Behbahan (8 accessions), 2 = Ahvaz (2 accessions), $3=$ Shiraz (2 accessions), $4=$ Birjand (1 accession), $5=$ Kerman $(2$ accessions), $6=$ Mehran (1 accession), 7 = Dareh shahr (1 accession), $8=$ Abdanan ( 1 accession), $9=$ Ghachsaran ( 2 accessions $), 10=$ Pol Dokhtar $(2$ accessions $)$, $11=$ Ghaem shahr ( 1 accession), $12=$ Rasht ( 2 accessions $), 13=$ Bavi ( 2 accessions $), 14=\operatorname{Jahrom}(2$ accessions $), 15=$ Kazerun $(1$ accession $), 16=$ exotic narcissus. 
well. The morpho-physiological traits were measured for accession clustering as either drought tolerant or drought sensitive using between-groups linkage of hierarchical cluster analysis by using the SPSS statistical package (version 16.0; IBM Corp., Armonk, NY).

\section{Results}

The selected primers generated 206 fragments (12.11 fragments per primer) ranging from 220 to $1700 \mathrm{bp}$ (Table 2). The highest number of fragments (23) was observed with primer 857 and the minimum number (6) was generated by primers 808 and 829 . In total, 198 fragments $(96.02 \%)$ were polymorphic. The maximum Rp value was 8.32 for primer 811 and the minimum value was for primers 809 and 827 (2). The major PIC value (0.44) was observed for primer 828 and the minor $(0.15)$ for primer 827 . The MI value varied from 0.73 (for primer 827) to 5.61 (for primer 811) (Table 2).

The maximum number of bands was generated for accession 19 (108) and the minimum were for 15 and 25 ( 77 and 78, respectively). Behbahan's population showed the highest percentage of polymorphic fragments $(51.94 \%)$ and the lowest percentage $(0.00 \%)$ was observed in Birjand, Mehran, Abdanan, Dareh Shahr, Kazerun, Rasht, and the exotic populations (Table 3).

The cophenetic coefficient of ISSR clustering from Jaccard's similarity matrix was $0.8882(P=0.001)$. To evaluate the genetic similarities, the $0 / 1$ matrix was used to construct a similarity matrix using Jaccard's coefficients. The similarity matrices then were applied to create a dendrogram using UPGMA. At the 0.23 level of similarity, the accessions formed two groups. All of the endemic narcissi from the different distribution areas of Iran were clustered in one group, and the exotic narcissus formed a separate cluster. Moreover, at the similarity coefficient of 0.55 , accession 4 (Meskin variant) separated from other accessions and formed a separate cluster. The dendrogram indicated that other endemic accessions were grouped into two main clusters. The initial main cluster was separated into two subclusters (A and B). Subcluster A contained 13 accessions of single-flower genotypes (Shahla; 6 accessions), semidouble flowers (2 accessions) and double

Table 5. Evaluation of physiological characteristics of 30 accessions of Narcissus tazetta, collected from different regions of Iran, under watersufficient condition. The data represent the average of six plants per treatment.

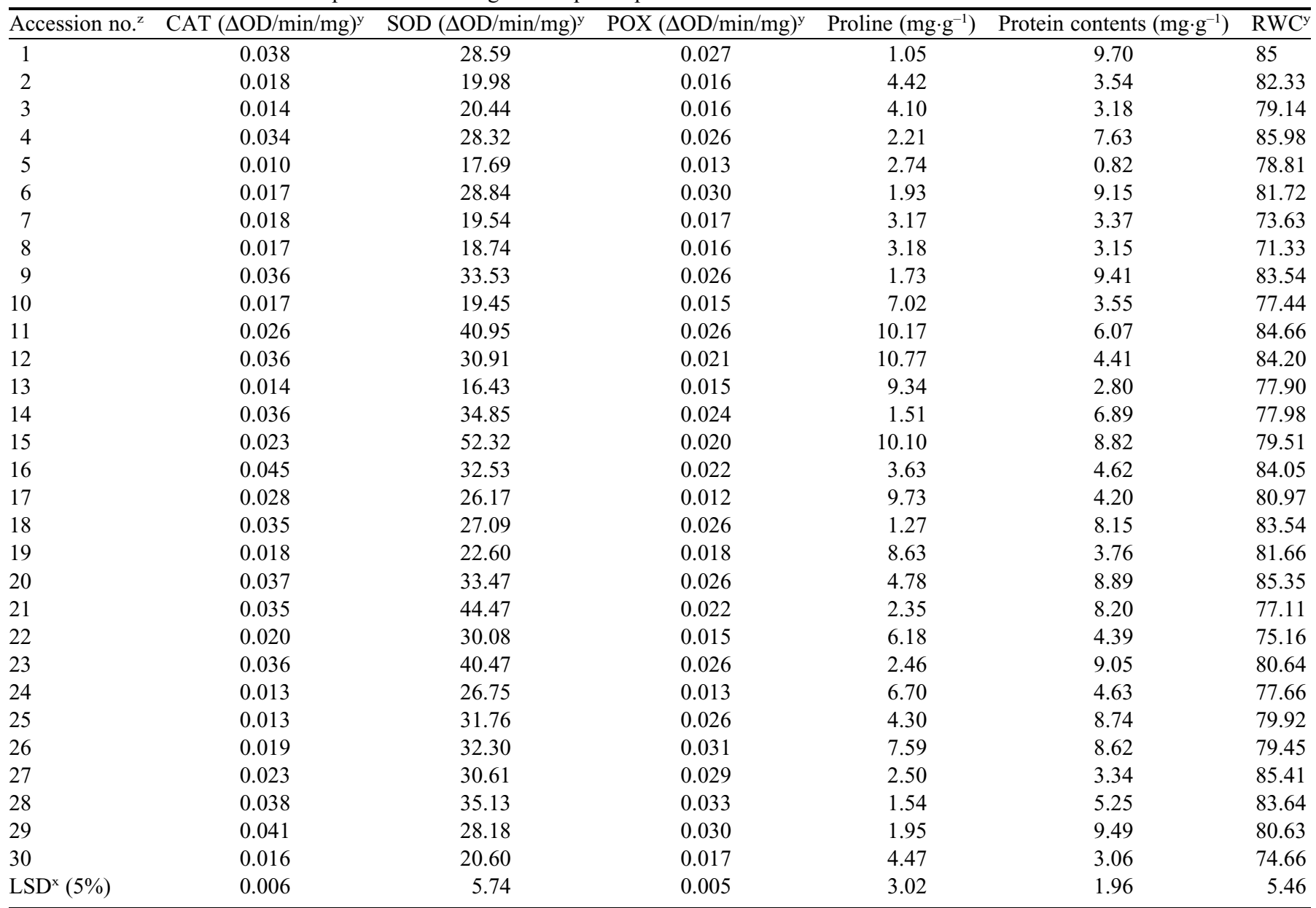

${ }^{\mathrm{z}} 1$ = Behbehan1, $2=$ Behbehan2, $3=$ Behbehan3, $4=$ Behbehan4, $5=$ Behbehan5, $6=$ Behbehan6, $7=$ Behbehan7, $8=$ Behbehan8, $9=$ Ahvaz1, $10=$ Ahvaz2, $11=$ Birjand, $12=$ Shiraz1, $13=$ Shiraz2, $14=$ Mehran, 15 = Dareh Shahr, 16 = Jahrom1, 17= Jahrom2, 18=Bavi1, 19= Bavi2, 20 = Kazerun, 21 = Pol Dokhtar1, $22=$ Pol Dokhtar3, $23=$ Gachsaran1, $24=$ Gachsaran3, $25=$ Kerman1, 26 = Kerman2, $27=$ Abdanan, $28=$ Ghaem Shahr, $29=$ Rasht $1,30=$ Rasht3.

${ }^{\mathrm{y}} \mathrm{CAT}=$ catalase, $\mathrm{OD}=$ optical density, $\mathrm{SOD}=$ superoxide dismutase, $\mathrm{POX}=$ peroxidase, $\mathrm{RWC}=$ relative water content.

${ }^{\mathrm{x}}$ Fisher's least significant difference (LSD) test at $P=0.05$. 
flowers (5 accessions). Subcluster B contained two accessions of Shahla with $60 \%$ similarity (Fig. 2). In each subcluster, single and double flowers formed separate clusters. Accession 5 fell between 3 (semidouble flower) and 7 (double flower) accessions. Based on Jaccard's similarity matrices, the similarity of accession 5 to 3 and 7 was $69 \%$ and $74 \%$, respectively. The accessions of Behbahan showed high diversity with the similarity of accessions of this region being 55\% (accession 4) to $85 \%$ (between accessions 7 and 8 ). The similarity of accession 6 to 1 (both single flowers collected from Behbahan) was $60 \%$ and formed an individual group that confirmed the morphological trait differences between accessions 6 and 1 .

The second main cluster was separated into two subclusters (C and D). Subcluster C comprised only accession 16 (single flower) and subcluster D comprised accessions with single flowers $(18,20,21,23,26,27,28$, and 29), semidouble flowers (22, 24, and 30) and double flowers (17 and 19), which formed separate groups.

The PCoA was applied based on the genetic distance matrix to better visualize the genetic relationships among the studied
Narcissus accessions. The overall grouping pattern in PCoA was similar to the clustering pattern in the dendrogram and confirmed the patterns of genetic variation observed among the accessions (Fig. 3). The exotic population did not group with the accessions in PCoA. The two principal axes showed $25.23 \%$ and $23.43 \%$ of the genetic variation, respectively.

Behbahan's population displayed the maximum percentage of polymorphism (51.94), the highest $\mathrm{Ne}$ (1.325), I (0.275), and He $(0.185)$. The minimum percentage of polymorphism $(0.00)$, the lowest $\mathrm{Ne}(1.000), \mathrm{I}(0.000)$, and He (0.000) were found in the populations of Mehran, Dareh Shahr, Abdanan, Ghaem Shahr, Kazerun, and the exotic narcissus (Table 3). On the basis of pairwise population matrix of Nei's (1978) unbiased genetic identity at the collecting region level, the greatest similarity (0.914) was perceived among the Behbahan and Kerman populations and the lowest similarity $(0.388)$ was observed between the Kazerun and exotic populations (Table 4).

The results indicate that the CAT, SOD, and POX contents, and also the proline and protein contents in response to water deficit increased (Tables 5 and 6). The UPGMA dendrogram of

Table 6. Evaluation of physiological characteristics of 30 accessions of Narcissus tazetta, collected from different regions of Iran, under waterdeficient condition. The data represent the average of six plants per treatment.

\begin{tabular}{|c|c|c|c|c|c|c|}
\hline Accession no. $^{z}$ & $\mathrm{CAT}^{\mathrm{y}}(\Delta \mathrm{OD} / \mathrm{min} / \mathrm{mg})^{\mathrm{y}}$ & $\mathrm{SOD}(\Delta \mathrm{OD} / \mathrm{min} / \mathrm{mg})^{\mathrm{y}}$ & $\mathrm{POX}(\Delta \mathrm{OD} / \mathrm{min} / \mathrm{mg})^{\mathrm{y}}$ & Proline $\left(\mathrm{mg} \cdot \mathrm{g}^{-1}\right)$ & Protein contents $\left(\mathrm{mg} \cdot \mathrm{g}^{-1}\right)$ & $\mathrm{RWC}^{\mathrm{y}}$ \\
\hline 1 & 0.154 & 92.13 & 0.093 & 50.72 & 21.85 & 67.16 \\
\hline 2 & 0.131 & 65.67 & 0.058 & 21.21 & 13.95 & 64.88 \\
\hline 3 & 0.130 & 92.25 & 0.059 & 20.35 & 13.44 & 63.82 \\
\hline 5 & 0.121 & 67 & 0.058 & 25.77 & 12.06 & 61.96 \\
\hline 6 & 0.136 & 92.61 & 0.080 & 52.34 & 21.61 & 68.15 \\
\hline 7 & 0.133 & 73.54 & 0.069 & 16.43 & 14.30 & 40.41 \\
\hline 9 & 0.149 & 82.48 & 0.100 & 31.46 & 21.89 & 67.25 \\
\hline 10 & 0.128 & 63.21 & 0.059 & 19.85 & 13.88 & 57.06 \\
\hline 11 & 0.135 & 70.19 & 0.086 & 34.25 & 18.02 & 65.50 \\
\hline 12 & 0.153 & 206.75 & 0.084 & 36.05 & 17.21 & 61.19 \\
\hline 13 & 0.128 & 65.89 & 0.046 & 20.96 & 13.38 & 55.68 \\
\hline 14 & 0.135 & 113.63 & 0.074 & 35.14 & 18.98 & 57.53 \\
\hline 19 & 0.128 & 66.99 & 0.046 & 20.43 & 12.68 & 59.05 \\
\hline 20 & 0.250 & 215.02 & 0.092 & 47.68 & 20.79 & 63.56 \\
\hline 21 & 0.139 & 94.03 & 0.068 & 39.33 & 25.49 & 49.62 \\
\hline 22 & 0.127 & 70.74 & 0.046 & 20.22 & 16.70 & 42.98 \\
\hline 23 & 0.142 & 81.46 & 0.072 & 32.56 & 24.99 & 57.81 \\
\hline 24 & 0.122 & 64.89 & 0.051 & 19.46 & 13.94 & 46.37 \\
\hline 25 & 0.131 & 154.65 & 0.055 & 29.41 & 16.81 & 42.54 \\
\hline 26 & 0.134 & 156.89 & 0.104 & 24.13 & 15.61 & 46.69 \\
\hline 27 & 0.132 & 86.84 & 0.088 & 44 & 15.93 & 65.36 \\
\hline 28 & 0.166 & 191.03 & 0.109 & 53.54 & 20.45 & 63.29 \\
\hline 29 & 0.147 & 95.12 & 0.114 & 47.81 & 21.45 & 61.16 \\
\hline
\end{tabular}

${ }^{\mathrm{z}} 1$ = Behbehan1, $2=$ Behbehan2, $3=$ Behbehan3, $4=$ Behbehan4, $5=$ Behbehan5, $6=$ Behbehan6, 7 = Behbehan7, $8=$ Behbehan8, $9=$ Ahvaz1, $10=$ Ahvaz2, $11=$ Birjand, $12=$ Shiraz1, 13 = Shiraz2, $14=$ Mehran, 15 = Dareh Shahr, 16 = Jahrom1, 17= Jahrom2, $18=$ Bavi1, 19= Bavi2, 20 = Kazerun, 21 = Pol Dokhtar1, $22=$ Pol Dokhtar3, $23=$ Gachsaran1, $24=$ Gachsaran3, $25=$ Kerman1, 26 = Kerman2, $27=$ Abdanan, $28=$ Ghaem Shahr, $29=$ Rasht $1,30=$ Rasht 3 .

${ }^{\mathrm{y}} \mathrm{CAT}=$ catalase, $\mathrm{OD}=$ optical density, $\mathrm{SOD}=$ superoxide dismutase, $\mathrm{POX}=$ peroxidase, $\mathrm{RWC}=$ relative water content.

${ }^{\mathrm{x}}$ Fisher's least significant difference (LSD) test at $P=0.05$. 
the physiological characteristics under the water-sufficient condition grouped the accessions into two main clusters. The first group had low antioxidant enzyme activity and low proline and protein contents. These comprised 12 accessions that included all of the double and semidouble flowers. Other accessions (single flowers) fell into the second group and showed more antioxidant enzyme activity and higher proline and protein contents (Fig. 4).

The UPGMA dendrogram of the morpho-physiological traits under drought stress indicate that accessions 16 and 20 (single flowers) were separate from the other accessions and formed a separate cluster. The dendrogram showed that other accessions were grouped into two major clusters. The first group was composed of 12 accessions with double and semidouble flowers, whereas the second group was composed of 16 accessions with single flowers. The first group was drought-sensitive and showed lower antioxidant activity, proline and protein contents, RWC, dry and fresh weight ratios, number of bulblets, and dry weight of bulb. The second group and accessions 16 and 20 were drought tolerant and had more distinct traits than the first group (Fig. 5).

A two-dimensional projection of the morphological and physiological characteristics of the Iranian Narcissus accessions grown under water-sufficient and water-stress conditions is shown in Figs. 6 and 7. The single and double flowers displayed considerable separation between the two wateraccessibility conditions.

\section{Discussion}

An understanding of the degree of genetic variation is important for prebreeding and breeding of germplasms and germplasm collection (Deore and Samantaray, 2015; Langridge and Chalmers, 2004). The current study is the first application of the ISSR method used to estimate genetic diversity and evaluate genetic relationships among 31 Narcissus accessions in Iran. The present investigation demonstrated a high degree of polymorphism among populations $(70 \%$ to $100 \%$, with an average of $96.02 \%$; Table 2). These primers also revealed similar results for Allium (Mukherjee et al., 2013) and Tulipa (Kiani et al., 2012), as well as some Iris (Raycheva et al., 2011) and Aloe (Deore and Samantaray, 2015) populations. The primers included (AG)8T, (AG) 8C, (AG)8G, (GA)8T, (GA)8C, (CA)8T, (AC)8T, (AG)8YC, (GA) 8YC, (ACA)5CYG, and (ACC)6, and were applied to estimate genetic diversity among important species of Allium, which generated an average $99.17 \%$ polymorphism. In species of Tulipa, the primers of (GA)8C, (AC)8T, (AC) 8G, (TG)8A, (TG)8C, (TG)8G, (AG)8YC, (GA)8YT, (CT)8RG, and (AC)8YT produced a total of 97 polymorphic bands. Hence, we decided these primers could be effective in determining the genetic diversity of other geophytes (e.g., Narcissus).

Polymorphism is produced by ISSR markers whenever one genome loses the sequence repeat or has a deletion, insertion, or translocation that changes the distance between two primer sites (Vijayan, 2005). The amount of polymorphism differs with the nature of the primer used (unanchored, 3'-anchored or $5^{\prime}$-anchored) and the sequence of the repeats (motif) in the primer. Whenever only SSRs (unanchored) 
are applied as primers, the primer tends to slide within the repeats during amplification and produce smears instead of clear bands [such as primer (ACC)6 (Table 2)] (Pradeep Reddy et al., 2002).

Generally, a high degree of polymorphism was observed in dinucleotide repeat units anchored either at the $3^{\prime}$ or $5^{\prime}$ ends (Blair et al., 1999; Joshi et al., 2000). The primers anchored at the $3^{\prime}$ end generate clearer bands than those anchored at the $5^{\prime}$ end (Blair et al., 1999; Nagaoka and Ogihara, 1997). Overall, primers based on the (AC), (CA), (CT), (TC), (AG), and (GA) repeat revealed higher polymorphism than primers with other di-, tri-, or tetranucleotide repeats. AT repeats were the most frequent dinucleotides in the plants; however, the primers with (AT) motifs tended to self-anneal and not amplify. ISSR primers with AT repeats are self-annealing and, because of sequence complementarity, they create dimers during PCR amplification (Blair et al., 1999; Mukherjee et al., 2013). Because of the decrease in

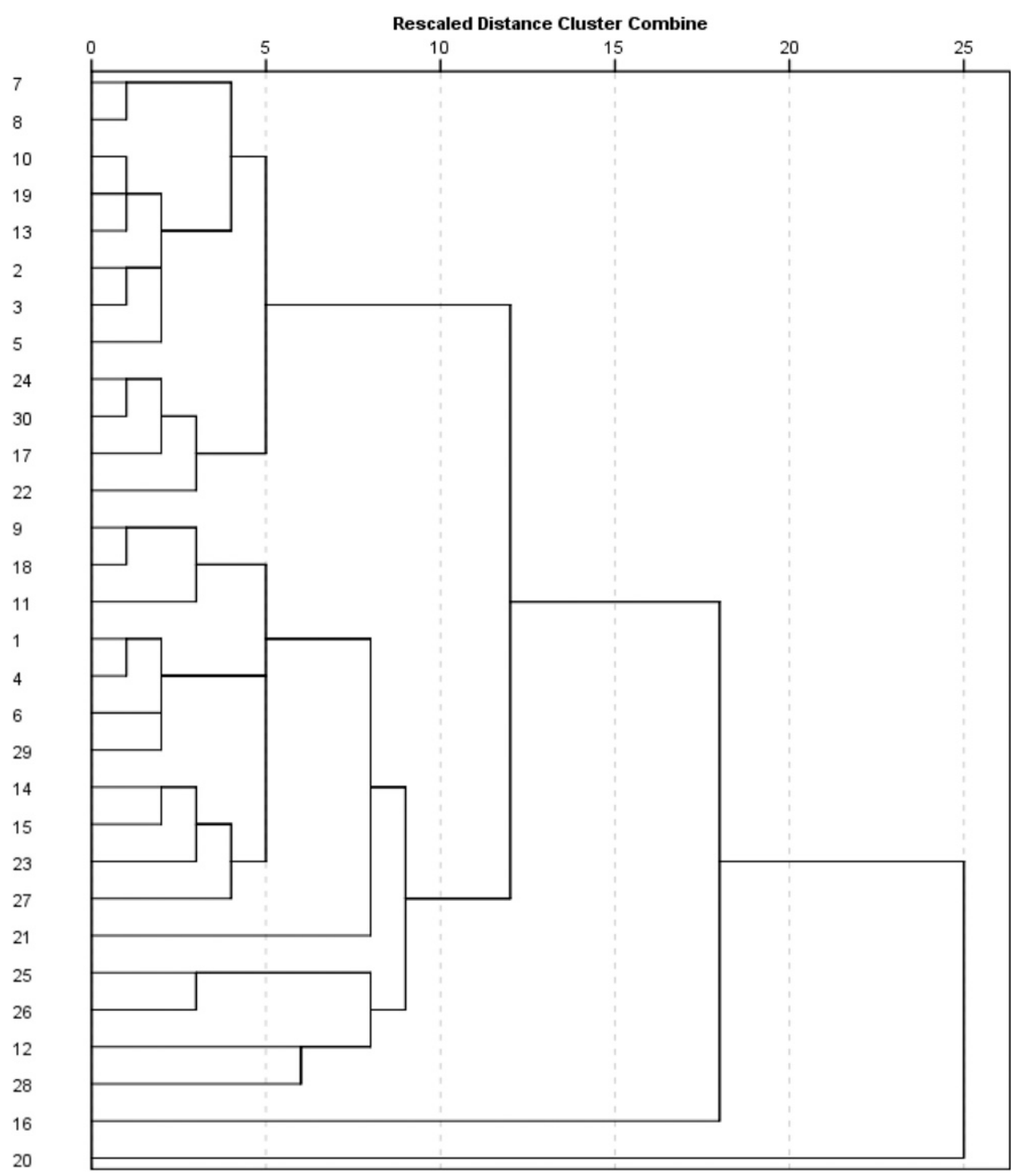

Fig. 5. Dendrogram of the physiological and morphological relationships under water-deficient condition between 30 accessions of Narcissus tazetta, collected from different regions of Iran: $1=$ Behbehan1, $2=$ Behbehan2, $3=$ Behbehan3, 4 = Behbehan4, 5 = Behbehan5, 6= Behbehan6, $7=$ Behbehan7, $8=$ Behbehan8, $9=$ Ahvaz1, $10=$ Ahvaz2, $11=$ Birjand, $12=$ Shiraz1, $13=$ Shiraz2, $14=$ Mehran, $15=$ Dareh Shahr, $16=$ Jahrom1, $17=$ Jahrom2, $18=$ Bavi1, $19=$ Bavi2, $20=$ Kazerun, $21=$ Pol Dokhtar1, $22=$ Pol Dokhtar3, $23=$ Gachsaran1, 24 = Gachsaran3, $25=$ Kerman1, $26=$ Kerman2, $27=$ Abdanan, $28=$ Ghaem Shahr, $29=$ Rasht1, $30=$ Rasht $3,31=$ exotic narcissus. abundance of the tri- and tetranucleotide repeats in plants, their application in primers is less than the dinucleotides (Pradeep Reddy et al., 2002; Vijayan, 2005). The findings of the present study illustrate that primers with (AG), (GA), and (CT) repeats produced clear band profiles. It suggests that these dinucleotides are the most abundant motifs in Narcissus. Similar results for poly(AG) and poly(GA) have been found in Allium, but (CT) repeats have not generated good profiles in Allium (Mukherjee et al., 2013). Primers synthesized from (CA) and (ACC) motifs did not amplify, even at a low annealing temperature. A feasible explanation for this is that the dispersion of these motifs in the Narcissus genome was outside the range of amplification of TaqDNA polymerase (Vijayan, 2005). The trinucleotide repeat primers based on (ACA) and (GTG) motifs generated excellent amplification.

In this investigation, PIC means ranged from 0.15 to 0.44 . PIC depends on the number of visible alleles and the distribution of their frequency corresponds to the gene diversity. The maximum limit of PIC in dominant markers is 0.5 (Botstein et al., 1980; De Riek et al., 2001). EMR ranged from 4.9 to 23 . Higher EMR values indicate that the primer/marker method is operative.

MI value ranged from 0.73 to 5.61. MI is a product of expected heterozygosity and EMR (Mukherjee et al., 2013). It is applied to estimate the overall effectiveness of a marker system and validate the effectiveness of the technique (Perez de la Torre et al., 2012; Powell et al., 1996). In this study, Rp varied from 2 to 8.32 . Rp is used to represent the ability of a primer/method to differentiate among large numbers of genotypes (Gilbert et al., 1999). Prevost and Wilkinson (1999) found that $\mathrm{Rp}$ can be used to evaluate the ability of each primer for differentiating among several accessions. In general, primers with a higher $\mathrm{Rp}$ value can better distinguish among accessions (Ghasemi Ghehsareh et al., 2014).

The results obtained with PCoA confirms that the ISSR primers were very effective for discriminating between the accessions. The results of PCoA and the dendrograms showed primarily similar clustering patterns. For instance, the PCoA plot placed accession 7 very close to 8 . On the basis of Jaccard's similarity matrices, the similarity of accessions 7 and 8 was $85 \%$. The close relationship between these could be the result of naturally occurring hybridization or mutation.

Behbahan's population showed a high percentage of polymorphism, Ne, I, and He. These results 
demonstrated that Behbahan is the eldest and premier Narcissus diversity center in Iran.

Principal component analysis is a common explorative method applied to decrease multivariate data complicacy.

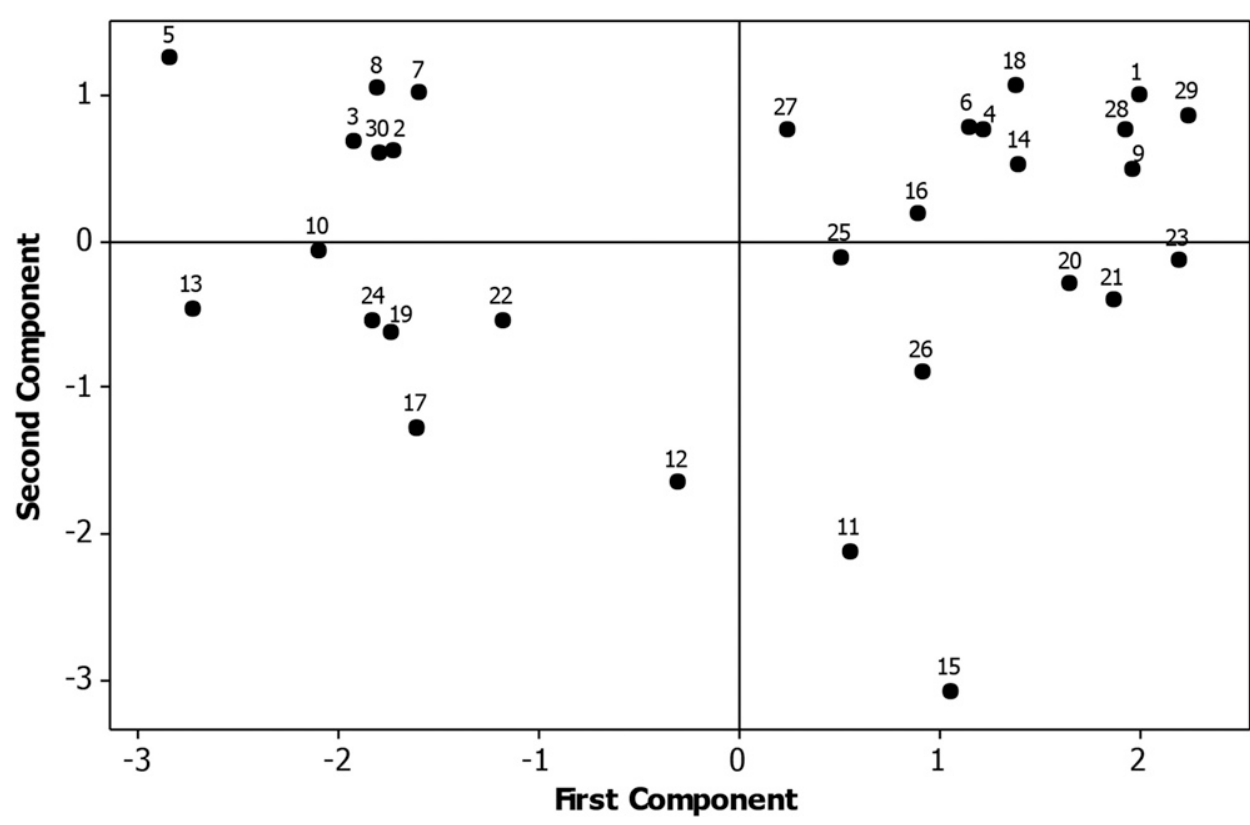

Fig. 6. Principal component analysis of physiological characteristics in 30 accessions of Narcissus tazetta under water-deficient condition collected from different regions of Iran: $1=$ Behbehan1, $2=$ Behbehan2, $3=$ Behbehan3, 4 = Behbehan4, $5=$ Behbehan5, $6=$ Behbehan6, $7=$ Behbehan7, $8=$ Behbehan8, $9=$ Ahvaz1, $10=$ Ahvaz2, $11=$ Birjand, $12=$ Shiraz1, $13=$ Shiraz2, $14=$ Mehran, $15=$ Dareh Shahr, $16=$ Jahrom1, $17=$ Jahrom2, $18=$ Bavi1 $19=$ Bavi2, 20 = Kazerun, $21=$ Pol Dokhtar1, $22=$ Pol Dokhtar3, $23=$ Gachsaran1, $24=$ Gachsaran3, $25=$ Kerman1, $26=$ Kerman2, 27 = Abdanan, $28=$ Ghaem Shahr, $29=$ Rasht1, $30=$ Rasht3.

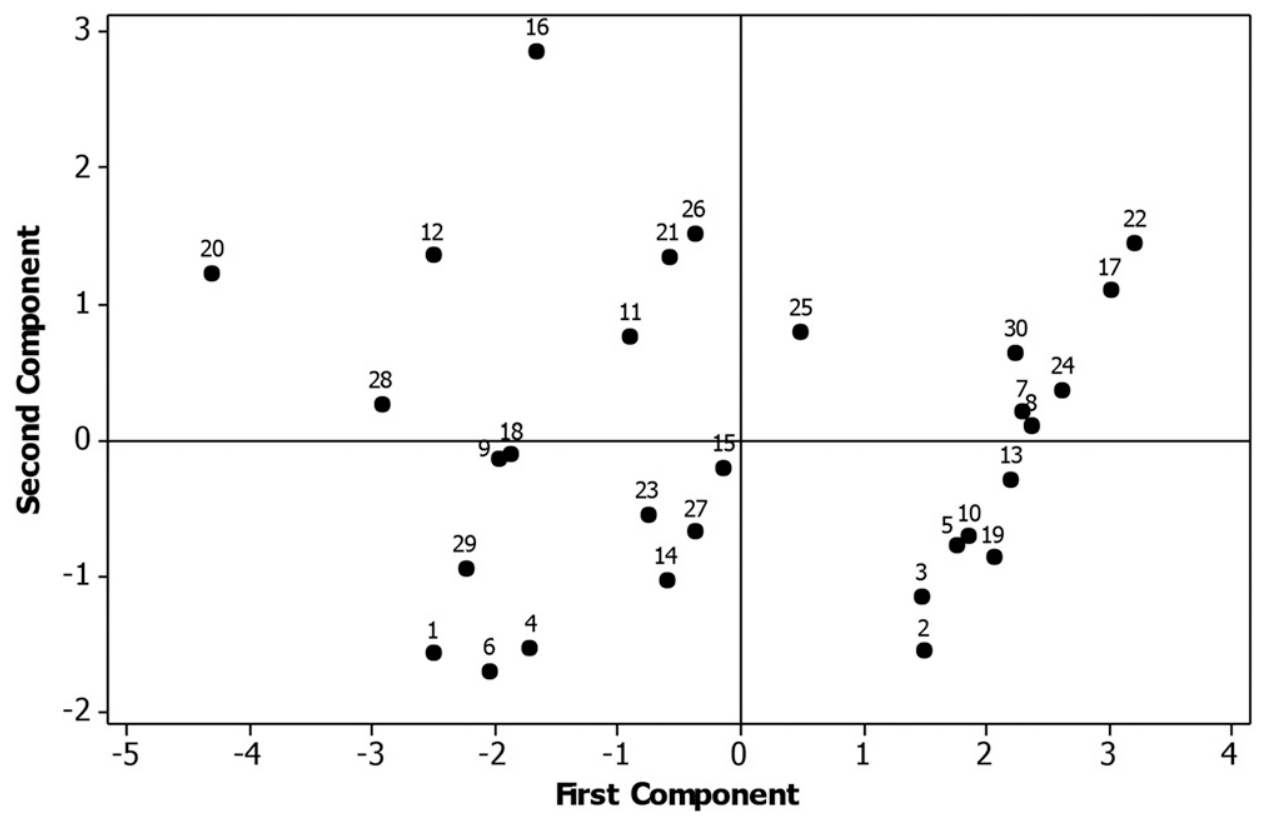

Fig. 7. Principal component analysis of morphological and physiological characteristics in 30 accessions of Narcissus tazetta under water-deficient condition collected from different regions of Iran: $1=$ Behbehan $1,2=$ Behbehan2, 3 = Behbehan3, 4= Behbehan4, 5= Behbehan5, $6=$ Behbehan6, $7=$ Behbehan7, $8=$ Behbehan8, $9=$ Ahvaz1, $10=$ Ahvaz2, $11=$ Birjand, $12=$ Shiraz1, $13=$ Shiraz2, $14=$ Mehran, $15=$ Dareh Shahr, $16=$ Jahrom1, $17=$ Jahrom2, 18 = Bavi1, $19=$ Bavi2, $20=$ Kazerun, $21=$ Pol Dokhtar1, $22=$ Pol Dokhtar3, $23=$ Gachsaran1, $24=$ Gachsaran3, $25=$ Kerman1, $26=$ Kerman2, $27=$ Abdanan, $28=$ Ghaem Shahr, $29=$ Rasht1, $30=$ Rasht3.
This method helps to identify similarities and differences between samples (Goodacre et al., 2000). The results showed that activity of antioxidant enzymes, such as CAT, SOD, and POX, in the accessions significantly increased during water stress (Tables 5 and 6). Similar results have been reported for maize [Zea mays (Bai et al., 2006)], chickpea [Cicer arietinum (Mafakheri et al., 2011)], and barley [Hordeum vulgare (Salekjalali et al., 2012)].

In response to environmental stresses such as drought, ROS such as hydroxyl radicals, superoxide, hydrogen peroxide, and singlet oxygen are produced and accumulate in plant cells (Jiang and Zhang, 2004). The protective mechanisms of tissues against ROS accumulation is related to their ability to break ROS down by increasing the activity of the antioxidant enzymes during water deficit. CAT, SOD, and POX are common and significant antioxidant enzymes that can destroy ROS (Capell et al., 2004; Saba et al., 2001). Reports have demonstrated that these antioxidant enzymes are higher in tolerant plants than in sensitive ones during water deficit (Bergmann et al., 1999; Gogorcena et al., 1995; Mafakheri et al., 2011; Shao et al., 2005).

The results of this study indicate that the CAT, SOD, and POX contents increased under drought stress, especially for tolerant accessions (Tables 5 and 6). Also, in response to water deficit, the proline and protein contents increased (Tables 5 and 6). When plants are exposed to drought stress, proline increases to high concentrations to protect cytoplasmic structures. Proline acts as an osmotic adjustment material and plays an important role as an osmoprotectant (Handa et al., 1983) for resistance and adaptation under water-deficient conditions (Hsiao, 1973).

The clustering pattern of the molecular markers showed that genotypes of different geographical regions could be grouped in one cluster and genotypes from similar ecological areas could be collected into one group or different clusters. This signifies that there was no proper connection between geographical variety and genetic variety. Other researchers (De and Rao, 1987; Garg and Kumar, 2017; Singh et al., 1987) have shown that 
geographical diversity is not necessarily correlated to genetic diversity. On the other hand, most single and double flowers in the same geographical area were grouped together into major groups and then formed separate subclusters. The current phylogenetic study showed that the morphological and physiological traits under water stress and the origin of accessions could be used to cluster them into three groups: very droughttolerant accessions collected from Fars province, Jahrom, and Kazerun regions (single flower); drought-tolerant accessions including other single flowers; and drought-sensitive accessions with double and semidouble flowers.

We found that accessions with a very low degree of similarity were not closely related genotypes and had different agronomic characteristics under water deficit. Similar results have been reported by Barakat et al. (2010) for Saudi wheat (Triticum aestivum) genotypes under drought stress.

\section{Conclusion}

The current study demonstrated that ISSR is an effective and informative molecular marker method for identifying genetic diversity of Narcissus accessions. The present study found that genetic variation did not necessarily coincide with morphological trait differences among Narcissus accessions. These results can be used in breeding programs on Narcissus genotypes. The genetic relationships among Narcissus accessions can be displayed more accurately by application of multiple DNA marker methods.

The morpho-physiological traits of the Iranian accessions can be clustered into two major groups: drought-tolerant accessions including single flowers and drought-sensitive accessions containing double and semidouble flowers. The findings of the present investigation can be used in future breeding programs for different Narcissus genotypes.

\section{Literature Cited}

Alam, A., M. Iqbal, and S. Vats. 2013. Cultivation of some overlooked bulbous ornamentals: A review on its commercial viability. Rpt. Opinion 5:9-34.

Artyushenko, Z.T. 1970. Amaryllidaceae of USSR, morphology, taxonomy and use. Nauka, Leningrad, Russia.

Baby, J. and D. Jini. 2011. Development of salt stress-tolerant plants by gene manipulation of antioxidant enzymes. Asian J. Agr. Res. 5:17-27.

Bai, L.P., F.G. Sui, T.D. Ge, Z.H. Sun, Y.Y. Lu, and G.S. Zhou. 2006. Effect of soil drought stress on leaf water status, membrane permeability and enzymatic antioxidant system of maize. Pedosphere 16:326-332.

Barakat, M.N., A.A. Al-Doss, K.A. Moustafa, E.I. Ahmed, and A.A. Elshafei. 2010. Morphological and molecular characterization of Saudi wheat genotypes under drought stress. J. Food Agr. Environ. 8:220-228.

Beauchamp, C. and I. Fridovich. 1971. Superoxide dismutases: Improved assays and an assay predictable to acrylamide gels. Ann. Biochem. 44:276-287.

Bergmann, H., B. Lippmann, V. Leinhos, S. Tiroke, and B. Machelett. 1999. Activation of stress resistance in plants and consequences for product quality. J. Appl. Bot. Food Qual. 73:153-161.

Blair, M.W., O. Panaud, and S.R. McCouch. 1999. Inter-simple sequence repeat (ISSR) amplification for analysis of microsatellite motif frequency and fingerprinting in rice (Oryza sativa L). Theor. Appl. Genet. 98:780-792.

Botstein, D., R.L. White, M. Skolnick, and R.W. Davis. 1980. Construction of a genetic linkage map in man using restriction fragment length polymorphisms. Amer. J. Hum. Genet. 32:314-331.
Capell, T., L. Bassie, and P. Christou. 2004. Modulation of the polyamine biosynthetic pathway in transgenic rice confers tolerance to drought stress. Proc. Natl. Acad. Sci. USA 101:9909-9914.

Chadha, S. and T. Gopalakaishna. 2007. Comparative assessment of REMP and ISSR marker assays for genetic polymorphism studies in Magna porthegrisea. Curr. Sci. 93:688-692.

Chance, B. and A.C. Maehly. 1955. Assay of catalases and peroxidases. Methods Enzymol. 2:764-775.

Chehrazi, M., R.A. Naderi, A.A. Shahnezhat Boushehri, and M.E. Hasani. 2008. Study of genetic diversity of exotic and endemic daffodils (Narcissus spp.) using RAPD markers. Intl. J. Hort. Sci. Technol. 8:225-236.

De Hertogh, A.A. and M. Le Nard. 1993. The physiology of flower bulbs: A comprenhensive treatise on the physiology and utilization of ornamental flowering bulbous and tuberous plants. Elsevier, Amsterdam, The Netherlands.

De Riek, J., E. Calsyn, I. Everaert, E. Van Bockstaele, and M. De Loose. 2001. AFLP based alternatives for the assessment of distinctness, uniformity and stability of sugar beet varieties. Theor. Appl. Genet. 103:1254-1265.

De, R.N. and A.V.S. Rao. 1987. Genetic divergence in rice under low land situation. J. Crop Improv. 14:128-131.

Deore, P. and S. Samantaray. 2015. Evaluation of genetic diversity of the important medicinal plant Aloe (Aloe barbadensis M.) using RAPD and ISSR markers. Intl. J. Agr. Sci. Res. 5:139-148.

Dhindsa, R.S., P. Plumb-Dhindsa, and T.A. Thorpe. 1981. Leaf senescence: Correlated with increased levels of membrane permeability and lipid peroxidation, and decreased levels of superoxide dismutase and catalase. J. Expt. Bot. 32:93-101.

Doyle, J.J. and J.L. Doyle. 1990. Isolation of plant DNA from fresh tissue. Focus 12:13-15.

Estoup, A. and B. Angers. 1998. Microsatellites and minisatellites for molecular ecology: Theoretical and empirical considerations, p. 5586. In: G.R. Carvalho (ed.). Molecular ecology: Origins and approach. IOS Press, Amsterdam, The Netherlands.

Fang, D.Q., M.L. Roose, R.R. Krueger, and C.T. Federici. 1997. Fingerprinting trifoliate orange germplasm accessions with isozymes, RFLPs, and inter-simple sequences repeat markers. Theor. Appl. Genet. 95:211-219.

Fernandes, A. 1968. Improvement in the classification of the genus Narcissus L. Plant Life 24:51-57.

Foyer, C.H., L. Maud, and K.J. Kunert. 1994. Photooxidative stress in plants. Physiol. Plant. 92:696-717.

Garg, H.S. and R. Kumar. 2017. Genetic diversity of drought tolerant rice (Oryza sativa L.) genotypes under drought stress condition. Intl. J. Chem. Studies 5:751-757.

Ghasemi Ghehsareh, M., H. Salehi, M. Khosh-Khui, and A. Niazi. 2014. Application of ISSR markers to analyze molecular relationships in Iranian jasmine (Jasminum spp.) accessions. Mol. Biotechnol. 57:65-74.

Gilbert, J.E., R.V. Lewis, M.J. Wilkinson, and P.D.S. Caligari. 1999. Developing an appropriate strategy to assess genetic variability in plant germplasm collections. Theor. Appl. Genet. 98:1125-1131.

Godwin, I.D., E.A.B. Aitken, and L.W. Smith. 1997. Application of inter-simple sequence repeat (ISSR) markers to plant genetics. Electrophoresis 18:1524-1528.

Gogorcena, Y., I. Iturbe-Ormaetxe, P.R. Escuredo, and M. Becana. 1995. Antioxidant defenses against activated oxygen in pea nodules subjected to water stress. J. Plant Physiol. 108:753-758.

Goodacre, R., B. Shann, R.J. Gilbert, E.M. Timmins, and A.C. McGovern. 2000. Detection of the dipicolinic acid biomarker in Bacillus spores using curie-point pyrolysis mass spectrometry and fourier transform infrared spectroscopy. Anal. Chem. 72:119127.

Gupta, M., Y.-S. Chyi, J. Romero-Severson, and J.L. Owen. 1994. Amplification of DNA markers from evolutionarily diverse genomes using single primers of simple-sequence repeats. Theor. Appl. Genet. 89:998-1006. 
Handa, S., R.A. Bressan, A.K. Handa, N.C. Carpita, and P.M. Hasegawa. 1983. Solutes contribution to osmotic adjustment in cultured plant cells adapt to water stress. Plant Physiol. 73:834-843. Hanks, G.R. (ed.). 2003. Narcissus and daffodil: The genus Narcissus. CRC Press, Boca Raton, FL.

Hodgins, K.A. and S.C.H. Barrett. 2007. Population structure and genetic diversity in tristylus Narcissus triandrus: Insights from microsatellite and chloroplast DNA variation. Mol. Ecol. 16:2317-2332.

Hsiao, T.C. 1973. Plant responses to water stress. Annu. Rev. Plant Physiol. 24:519-570.

Jiang, M.Y. and J.H. Zhang. 2004. Abscisic acid and antioxidant defense in plant cells. Acta Bot. Sin. 46:1-9.

Joshi, S.P., V.S. Gupta, R.K. Aggarwal, P.K. Ranjekar, and D.S. Brar. 2000. Genetic diversity and phylogenetic relationship as revealed by inter-simple sequence repeat (ISSR) polymorphism in the genus Oryza. Theor. Appl. Genet. 100:1311-1320.

Kamenetsky, R. and H. Okubo. 2013. Ornamental geophytes: From basic science to sustainable production. CRC Press, Boca Raton, FL. Khamidkhodzhaev, S.A. 1984. Biology, resources and introduction of medicinal plants of Ungernia Bunge and Ficus L. in Middle Asia. Main Botanical Garden, Moscow, Russia, Dr. Sci. Diss. Abstr.

Kiani, M., F. Memariani, and H. Zarghami. 2012. Molecular analysis of species of Tulipa L. from Iran based on ISSR markers. Plant Syst. Evol. 298:1515-1522.

Langridge, P. and K. Chalmers. 2004. The principle: Identification and application of molecular markers, p. 3-22. In: H. Lorz and G. Wenzel (eds.). Molecular marker systems in plant breeding and crop improvement. Springer, Berlin, Germany.

Lu, G., Z. Xiaoying, Z. Yijing, Z. Qingch, X. Xun, and C. Jiashi. 2007. Effect of radiation on Chinese Narcissus and analysis of genetic variation with AFLP and RAPD markers. Plant Cell Tissue Organ Cult. 88:319-327.

Mafakheri, A., A. Siosemardeh, B. Bahramnejad, P.C. Struik, and Y. Sohrabi. 2011. Effect of drought stress and subsequent recovery on protein, carbohydrate contents, catalase and peroxidase activities in three Chickpea (Cicer arietinum) cultivars. Austral. J. Crop Sci. 5:1255-1260.

Mantel, N. 1967. The detection of disease clustering and a generalized regression approach. Cancer Res. 27:209-220.

McCough, S.R., X. Chen, O. Panaud, S. Temnykh, Y. Xu, Y.G. Cho, and M. Blair. 1997. Microsatellite marker development, mapping and applications in rice genetics and breeding. Plant Mol. Biol. 35:89-99.

Medrano, M., E. Lopez-Perea, and C.M. Herrera. 2014. Population genetics methods applied to a species delimitation problem: Endemic trumpet daffodils (Narcissus section Pseudonarcissi) from the southern Iberian peninsula. Intl. J. Plant Sci. 175:501-517.

Meyer, W., T.G. Mitchell, E.Z. Freedman, and R. Vilgays. 1993. Hybridization probes for conventional DNA fingerprinting used as single primers in the polymerase chain reaction to distinguish strains of Cryptococcus neoformans. J. Climatol. Microbiol. 31:22742280.

Monforte, A.J., J. Garcia-Mas, and P. Arus. 2003. Genetic variability in melon based on microsatellite variation. Plant Breed. 122:153157.

Mukherjee, A., B. Sikdar, B. Ghosh, A. Banerjee, E. Ghosh, M. Bhattacharya, and S.C. Roy. 2013. RAPD and ISSR analysis of some economically important species, varieties, and cultivars of the genus Allium (Alliaceae). Turk. J. Bot. 37:605-618.

Nagaoka, T. and Y. Ogihara. 1997. Applicability of inter simple sequence repeat polymorphisms in wheat for use as DNA markers in comparison to RFLP and RAPD markers. Theor. Appl. Genet. 94:597-602.

Nayanakantha, N.M.C., B.R. Singh, and A.K. Gupta. 2010. Assessment of genetic diversity in Aloe germplasm accessions from India using RAPD and morphological markers. Ceylon J. Sci. 39:1-9.

Nei, M. 1978. Estimation of average heterozygosity and genetic distance from a small number of individuals. Genetics 89:583-590.
Peakall, R. and P. Smouse. 2006. GENALEX 6: Genetic analysis in Excel. Population genetic software for teaching and research. Mol. Ecol. Notes 6:288-295.

Perez de la Torre, M., M. Garcia, R. Heinz, and A. Escandon. 2012. Analysis of genetic variability by ISSR markers in Calibra choacaesia. Electron. J. Biotechnol. 15:1-12.

Pigni, N.B., S. Berkov, A. Elamrani, M. Benaissa, F. Viladomat, C. Cordina, and J. Bastida. 2010. Two new alkaloids from Narcissus serotinus L. Molecules 15:7083-7089.

Pivoriene, O. and I. Pasakinskiene. 2008. Genetic diversity assessment in perennial ryegrass and Festulolium by ISSR fingerprinting. Zemdirbyste 95:125-133.

Powell, W., M. Morgante, C. Andre, M. Hanafey, J. Vogel, S. Tingey, and A. Rafalsky. 1996. The comparison of RFLP, RAPD, AFLP, and SSR (microsatellite) markers for germplasm analysis. Mol. Breed. 2:225-238.

Pradeep Reddy, M., N. Sarla, and E.A. Siddiq. 2002. Inter simple sequence repeat (ISSR) polymorphism and its application in plant breeding. Euphytica 128:9-17.

Prevost, A. and M.J. Wilkinson. 1999. A new system of comparing PCR primers applied to ISSR fingerprinting of potato cultivars. Theor. Appl. Genet. 98:107-112.

Qian, W., S. Ge, and D.Y. Houng. 2001. Genetic variation within and among populations of a wild rice Oryza granulata from China detected by RAPD and ISSR markers. Theor. Appl. Genet. 102:440-449.

Qian, X., C.X. Wang, and M. Tian. 2013. Genetic diversity and population differentiation of Calanthe tsoongiana, a rare and endemic orchid in China. Intl. J. Mol. Sci. 14:20399-20413.

Rahimizadeh, M., D. Habibi, H. Madani, G.N. Mohammadi, A. Mehraban, and A.M. Sabet. 2007. The effect of micronutrients on antioxidant enzymes metabolism in sunflower (Helianthus annuus L.) under drought stress. Helia 30:167-174.

Raycheva, T., K. Stoyanov, and I. Denev. 2011. Genetic diversity and molecular taxonomy study of three genera from Iridaceae family in the Bulgarian flora based on ISSR markers. Biotechnol. Biotechnol. Equip. 25:2484-2488.

Rohlf, F.J. 1998. NTSYSpc: Numerical taxonomy and multivariate analysis system. Version 2.02. Exeter Publ., Setauket, NY.

Ruiz-Ramon, F., D.J. Aguila, M. Egea-Cortines, and J. Weiss. 2014. Optimization of fragrance extraction: Daytime and flower age affect scent emission in simple and double narcissi. Ind. Crops Prod. 52:671-678.

Saba, J., M. Moghaddam, and K. Ghassemi. 2001. Genetic properties of drought resistance indices. J. Agr. Sci. Technol. 3:43-49.

Salehi, M., H. Salehi, A. Niazi, and C. Ghobadi. 2014. Convergence of goals: Phylogenetical, morphological, and physiological characterization of tolerance to drought stress in tall fescue (Festuca arundinacea Schreb.). Mol. Biotechnol. 56:248-257.

Salekjalali, M., R. Haddad, and B. Jafari. 2012. Effects of soil water shortages on the activity of antioxidant enzymes and the contentes of chlorophylls and proteins in barley. Amer.-Eurasian J. Agr. Environ. Sci. 12:57-63.

Shao, H.B., Z.S. Liang, and M.A. Shao. 2005. Changes of some antioxidative enzymes under soil water deficits among 10 wheat genotypes at maturation stage. Colloids Surfaces Biointerfaces 45:7-13.

Shi, A., S. Kantartzi, M. Mmbaga, and P. Chen. 2010. Development of ISSR PCR markers for diversity study in dogwood (Cornus spp.). Agr. Biol. J. North Amer. 1:189-194.

Singh, S.K., R.S. Singh, D.M. Maurya, and O.P. Verma. 1987. Genetic divergence among the low land rice cultivars. Indian J. Genet. Plant Breed. 39:315-322.

Tautz, D. and M. Renz. 1984. Simple sequences are ubiquitous repetitive components of eukaryotic genomes. Nucleic Acids Res. 12:4127-4138.

Toker, C., C. Lluch, N.A. Tejera, R. Serraj, and K.H.M. Siddique. 2007. Abiotic stresses, p. 474-496. In: S.S. Yadav, R.J. Redden, W. Chen, and B. Sharma (eds.). Chickpea breeding and management. CABI Publ., London, UK. 
Tucci, G.F., M.O. Winfield, G.F.D. Amato, C. Gregori, B. Trombetta, and R.I. De Dominicis. 2004. Genetic diversity in Narcissus poeticus L. and $N$. radiiflorus Salisb. (Amaryllidaceae) in two different populations: AFLP and karyological studies. Caryologia 57:405-411. Vijayan, K. 2005. Inter simple sequence repeat (ISSR) polymorphism and its application in Mulberry genome analysis. Intl. J. Ind. Entomol. 10:79-86.

Weising, K., H. Nybom, M. Pfenninger, K. Wolff, and G. Kahl. 2005. DNA fingerprinting in plants: Principles, methods and applications. CRC Press, Boca Raton, FL.
Wu, K., R. Jones, L. Dannaeberger, and P.A. Scolnik. 1994. Detection of microsatellite polymorphisms without cloning. Nucleic Acids Res. 22:3257-3258.

Yong, T., L. Zongsuo, S. Hongbo, and D. Feng. 2006. Effect of water deficits on the activity of antioxidative enzymes and osmoregulation among three different genotypes of Radix astragali at seeding stage. Colloids Surfaces Biointerfaces 49:60-65.

Zietkiewicz, E., A. Rafalski, and D. Labuda. 1994. Genome fingerprinting by simple sequence repeat (SSR)-anchored polymerase chain reaction amplification. Genomics 20:176-183. 